\title{
Different pre-implantation phenotypes of bovine blastocysts produced in vitro
}

\author{
Isabelle Hue ${ }^{1}$, Isabelle Dufort ${ }^{2}$, Anaïs Vitorino Carvalho ${ }^{1,3}$, Denis Laloe ${ }^{4}$, Nathalie Peynot ${ }^{1}$, \\ Séverine Aude Degrelle $5,6,7$, Christoph Viebahn ${ }^{8}$ and Marc-André Sirard ${ }^{2}$ \\ ${ }^{1}$ UMR BDR, INRA, ENVA, Université Paris Saclay, Jouy en Josas, France, ${ }^{2}$ Centre de Recherche en Biologie de la \\ Reproduction, Département des Sciences Animales, Faculté des Sciences de l'Agriculture et de l'Alimentation, \\ Université Laval, Quebec City, Québec, Canada, ${ }^{3} U M R$ PRC, INRA, CNRS, IFCE, Université de Tours, Nouzilly, \\ France, ${ }^{4}$ UMR GABI, INRA, Université Paris Saclay, Jouy en Josas, France, ${ }^{5}$ INSERM, UMR-S1139, Faculté de \\ Pharmacie de Paris, Paris, France, ${ }^{6}$ Université Paris Descartes, Sorbonne Paris Cité, Paris, France, ${ }^{7}$ Inovarion, Paris, \\ France and ${ }^{8}$ Institute of Anatomy and Embryology, University Medical Centre Göttingen, Göttingen, Germany
}

Correspondence should be addressed to I Hue; Email: isabelle.hue@inra.fr

\begin{abstract}
Embryo transfer in cattle is performed with blastocysts produced in vivo or in vitro using defined media. However, outdated systems such as those that use serum and co-culture remain of interest for research purposes. Here, we investigated the effect of additional culture time on in vitro-produced embryos. Specifically, we compared embryos that formed a blastocoel at different times after fertilisation to those that stayed in culture for up to two additional days with respect to their development in vivo after temporary transfer to oestrus-synchronised recipients. A pre-transfer set (D6, D6+1, D6+2, D7, D7+1, D8) was examined using microarray analyses and correlated with a post-transfer set that included two different days of transfer (D6-T6, D6+2-T8, D7+1-T8, D8-T8). All surviving conceptuses reached primitive-streak stages and filamentous sizes similarly to in vivo (D18) or in vitro controls (D7/T7). The recovery rate differed between D6 and D8 embryos that were immediately transferred (58 vs $25 \%$ ). With an intermediate survival rate $(33 \%)$, the D6 embryos with two additional days in culture produced nine times more IFN-tau (IFNT) at D18 than the D6 embryos that were immediately transferred. At the end of culture, D6 and D6+2 embryos displayed the highest number of gene expression differences. Despite a mortality of 40-60\%, no signature was detectable in any of the transferred groups that would account for the embryos' fates. Initially reputed to be beneficial in producing more blastocysts, our culture system of B2 medium plus serum and co-culture generated blastocysts that were distinct from those developed in vivo (D7).

Reproduction (2019) 157 163-178
\end{abstract}

\section{Introduction}

Embryo transfer (ET) is used worldwide in cattle as a basis for genomic selection to improve animal productivity (Hasler 2014, Stroebech et al. 2015). The embryos used in this process can be produced either in vivo or in vitro. Although in vitro culture conditions have been optimised over the years, they do not perfectly mimic the environment of the oviduct. Embryos must therefore compensate for this as much as they are able to, activating survival processes such as the oxidative stress response and changes in cellular metabolism (for example, Thompson et al. 2007, Bertoldo et al. 2015). Furthermore, once transferred to the uterus of synchronised recipients, not all embryos reach term and live birth. Indeed, $40 \%$ are lost between days 8 and 17 (Mamo et al. 2011) so that about $60 \%$ survive until D17 (Farin et al. 2001), a time at which pregnancy is recognised in the mother through the secretion of IFNtau (IFNT; Lonergan et al. 2016, Bazer et al. 2018), a cytokine whose expression is temporally and spatially regulated (Ealy \& Yang 2009, Sakurai et al. 2013).

Increasing the survival rate has thus been a major goal of the scientific community. This has led to the optimisation of many aspects of ET protocols, including recipient management, time of transfer or the number of embryos per transfer (Jones \& Lamb 2008, Berg et al. 2010, Randi et al. 2016). While one embryo per recipient is the gold standard, research efforts sometimes involve the transfer of multiple embryos in order to evaluate the quality of in vitro-produced embryos. The features of these embryos are then compared with developmental landmarks for blastocyst elongation and gastrulation known from in vivo blastocyst differentiation (MaddoxHyttel et al. 2003, Hue 2016). Generally speaking, multiple ETs led to either (i) lower retrieval rates and reduced average conceptus length in some but not all cases (Berg et al. 2010), number of embryos transferred per recipient: $n=3-30$; but see (Clemente et al. 2009, 
Machado et al. 2013) or (ii) the development of smaller or no embryonic discs or deficient gastrulation or neurulation patterns (Fischer-Brown et al. 2004, Alexopoulos et al. 2008, Machado et al. 2013, van Leeuwen et al. 2015).

Another feature of in vitro development that has been the target of optimisation studies is the culture system used. Many different media and culture systems have been proposed, with one of the first promising ones utilising co-culture with feeder cells (African green monkey kidney (VERO) cells, for instance: Desai \& Goldfarb 1998) on B2 medium supplemented with serum. Initially, it was found that co-culture with VERO cells increased the number of expanding and hatching human blastocysts with respect to single-culture conditions (Menezo et al. 1990). The same procedure was likewise found to produce more high-viability bovine blastocysts, leading to a pregnancy rate at D90 of 58\% (Menck et al. 1997). The feeder principle was concomitantly confirmed using other cells, such as buffalo rat liver or bovine oviduct epithelial cells (BRL, BOEC, Farin et al. 1997, Hasler 2000) on other serum-containing culture media (such as M-199, Catt 1994). Co-cultures ab initio appeared to support earlier formation of blastocysts and in higher numbers (Farin et al. 1997, Hasler 2000). A decade later it became clear, though, that in vitro culture induced gene expression changes in embryos and that high concentrations of human serum $(20 \%)$ in culture media generated developmental consequences that remained long after ETs were carried out (Sinclair et al. 1999, Rief et al. 2002). For this reason, in vitro-produced (IVP) embryos began to be commercially produced worldwide using semi-defined or fully defined media with no added serum or bovine serum albumin (BSA; Farin et al. 2001, Murillo-Rios et al. 2017).

Numerous studies have investigated the molecular changes at work in different IVP embryos (bovine, mouse, rabbit) in order to evaluate the influence of different parameters of culture systems on subsequent in vitro development (Gutierrez-Adan et al. 2015, Salvaing et al. 2016, Thompson et al. 2016, Duranthon \& Chavatte-Palmer 2018). This work has led to the recognition of signatures for certain in vitro culture conditions (Cagnone \& Sirard 2016, Feuer et al. 2017), but these have only rarely been compared to those of in vivo-developing embryos that are able to reach term (Ghanem et al. 2011, Gad et al. 2012a). Furthermore, a few studies have recently re-evaluated the use and impact of serum (Heras et al. 2016, Murillo et al. 2017) or feeder cells (BOEC; Schmaltz-Panneau et al. 2015) on embryos, while others have evaluated new options such as the use of oviductal and/or uterine fluids (Hamdi et al. 2018). For example, Cordova et al. (2014) obtained more blastocysts at D6 or D7 when BOECs were added to synthetic oviduct fluid (SOF) for 4 of the 8 days of culture. To the best of our knowledge, only one study to date has compared BOEC or VERO cells added to SOF with respect to their impact on the embryonic transcriptome (Vitorino Carvalho et al. 2017). However, no study has yet examined the molecular effects of co-culture in serum-containing B2 medium on the whole embryonic transcriptome. To investigate this, in this study, we used VERO cells in serum-containing B2 medium during the whole culture period to sort blastocysts that formed at D6, D7 or D8.

Since ET is classically performed at D7 or D8 using unsorted blastocysts, we also tested the effect of extending the culture time of the D6- or D7-forming embryos by 2 or 1 days, respectively, and transferring them at D8. Overall, we evaluated (i) molecular differences between these groups at the end of culture and (ii) the developmental features of a subset of embryos 10-12 days after temporary transfer in vivo. Using this system, we aimed to (i) tease apart the differences among embryos, which may be caused by their developmental potential or ability to compensate for a suboptimal culture environment and (ii) evaluate whether some of these compensatory/adaptive pathways would resemble those reported for the embryos of wild species that pause their development, in a reversible manner, in response to unfavourable conditions (diapause; Fenelon et al. 2014).

\section{Materials and methods}

All experiments were conducted in accordance with the International Guiding Principles for Biomedical Research Involving Animals as promulgated by the Society for the Study of Reproduction.

\section{Definition of embryo groups to be compared}

We wanted to evaluate whether embryos that formed a blastocyst cavity at different times after fertilisation would develop equally well after in vivo transfer if cultured for up to 2 more days. To do this, we first randomly assigned presumptive zygotes to microdrops of B2 medium that contained foetal calf serum (FCS, 5\%) and were co-cultured with VERO cells, under oil. Blastocysts forming at D6, D7 or D8 were sorted, scored on the basis of previous reports (Mori et al. 2002, Hoelker et al. 2006) and assigned to new drops at each evaluation. For the post-transfer analysis, we included only those groups transferred at the earliest (D6) or latest (D8) days of transfer; D7 and D6+1 blastocysts were not transferred into oestrus-synchronised recipients at D7. As shown in Fig. 1, we therefore created the following four experimental groups: (i) blastocysts that formed early (at D6) and were transferred at D6 (experimental group D6-T6); (ii) blastocysts that formed early (D6) and were maintained in culture for two additional days before being transferred at D8 (experimental group D6+2-T8); (iii) blastocysts that formed at D7 and were maintained one extra day in culture before being transferred at D8 (experimental group D7+1-T8) and (iv) blastocysts that formed at D8 and were transferred at D8 (experimental group D8-T8). Blastocysts were recorded as expanded (i.e. those formed at D6 or D8), as intermediate or close to hatching 


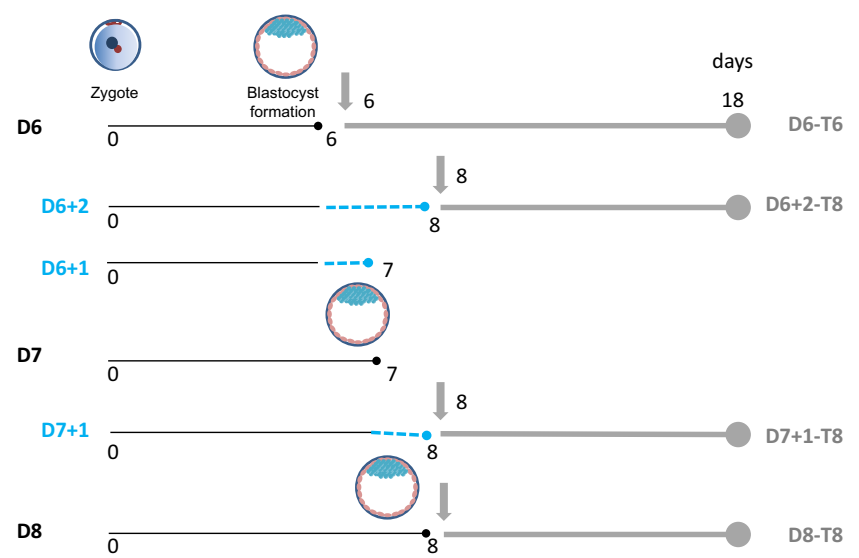

Figure 1 Experimental design. After in vitro fertilisation, bovine zygotes were cultured in batches of 25 embryos in $50 \mu \mathrm{L}$ drops, at $39^{\circ} \mathrm{C}$ with $5 \% \mathrm{O}_{2}, 5 \% \mathrm{CO}_{2}$ and $90 \% \mathrm{~N}_{2}$, until blastocoels formed at D6, D7 or D8 (D6 to D8, in black). For the in vitro-extended group, blastocysts that formed at D6 or D7 were maintained in culture for one or two additional days, up to a total culture time of eight days (D7+1, D6+1, D6+2, in blue). A subset of newly formed (D6, D8) or in vitro-extended $(\mathrm{D} 6+2 ; \mathrm{D} 7+1)$ blastocysts (grade 1-2) were transferred to oestrus-synchronised recipient heifers at D6 (T6) or D8 (T8) to evolve in utero up to D18 (D6-T6, D6+2-T8, D7+1-T8, D8-T8). Thin black line: in vitro development; thick dashed blue line: additional day in culture after blastocyst formation $(+1$ or +2$)$; thick grey line: in utero development; grey arrows: time of in utero transfer; small (black and blue) points: time of blastocyst sampling for molecular profiling; large grey point: time of conceptus flushing for developmental evaluation and quantification of IFN-tau production.

(D6+1, D7), or as hatched (D7+1, D6+2). These experimental groups were compared with a control dataset obtained from in vivo D7 blastocysts, which had been previously analysed in another study conducted by the EmbryoGENE network (Gad et al. 2012a). Additional control data were obtained from embryos that experienced full in vivo development up to D18 as well as classical D7-T7 embryos, both of which also originated from another study which used the identical IVP system (culture in B2 medium plus FCS with VERO cells: (Degrelle et al. 2012)). In sum, six pre-transfer and four posttransfer experimental groups were evaluated: the pre-transfer set (D6, D6+1, D6+2, D7, D7+1, D8) was examined using microarray profiles (see below), while the post-transfer set (D6-T6, D6+2-T8, D7+1-T8, D8-T8; Fig. 1) was evaluated with respect to differences in conceptus recovery rate, morphology, Brachyury (TBXT) mRNA expression and IFNT Western blots.

\section{In vitro-produced blastocysts}

Briefly, cow ovaries were collected at a local slaughterhouse and transported within $3 \mathrm{~h}$ to the laboratory in phosphatebuffered saline (PBS, BR0014G, Oxoid Limited, Basingstoke, UK) at $30^{\circ} \mathrm{C}$. Immature oocytes were aspirated from antral follicles $(2-7 \mathrm{~mm}$ in diameter), and we selected cumulusoocyte complexes (COCs) with more than three compact layers of cumulus cells. These were pooled and rinsed in fresh medium before maturation. The COCs were cultured for $24 \mathrm{~h}$ at $39^{\circ} \mathrm{C}$ under a humidified atmosphere of $5 \% \mathrm{CO}_{2}$ in air. At the end of the maturation period, the oocytes were fertilised in vitro in TALP medium supplemented with $1 \mu \mathrm{g}$ heparin $/ \mathrm{mL}$ (H3149, Sigma-Aldrich) and PHE (Penicillamine-HypotaurineEpinephrine). Frozen semen from a single bull was used in all the in vitro experiments; this was the same semen that Degrelle et al. (2012) used to produce their in vivo D18 and D7-T7 controls (but different from that used for the in vivo D7 by Gad et al. (2012a)). Sperm was added at a concentration of $10^{6} \mathrm{spermatozoa} / \mathrm{mL}$ and the day of in vitro insemination was denoted D0. Eighteen hours after insemination, COCs were removed from the fertilisation medium; presumptive zygotes were denuded of cumulus cells by vortexing and randomly assigned to microdrops. In vitro development up to the blastocyst stage was carried out using the co-culture technique with VERO cells as reported in Menck et al. (1997). Blastocyst formation was evaluated successively at days 6,7 and 8 postinsemination but total, ICM or TE cell numbers were not determined. At each evaluation, newly formed blastocysts were isolated and scored. Some blastocysts that formed on D6 or D7 were selected to remain in culture for an additional 1 or 2 days. In general, the phenotypes of D6 and D8 blastocysts were recorded as expanded (diameter of 165-180 $\mu \mathrm{m}$, ZP-enclosed), the intermediate groups (D6+1, D7) were close to hatching (diameter of $200-220 \mu \mathrm{m}$, breaking ZP) and the two groups that spent the longest time in culture $(D 7+1, D 6+2)$ were hatched (diameter of $230-250 \mu \mathrm{m}$, re-expanded after hatching). Degeneration of the zona pellucida was observed in about $1 \%$ of most groups, in $5 \%$ of the most-extended in vitro group $(\mathrm{D} 6+2)$ and in $10 \%$ of the late-forming blastocysts (D8). Only high-grade embryos (Q1, or 80\% Q1-20\% Q2) were transferred, and transfer was performed within the $2 \mathrm{~h}$ following the end of IVP. Embryos destined for molecular profiling were washed twice in sterile PBS, and then frozen and stored at $-80^{\circ} \mathrm{C}$ for subsequent RNA extraction. All groups of blastocysts were collected from multiple IVP replicates and pooled ( $n=15-20$ per sample for array hybridisation; three replicates per group; $n=25-45$ per sample for RT-qPCR; three replicates per group).

\section{Temporary transfer of in vitro-produced blastocysts}

Beef-breed heifers were treated to induce oestrus synchronisation (Crestar; Intervet, France). Each heifer received six blastocysts that were non-surgically transferred at D6 or D8. Two recipient heifers were used per blastocyst group (D6, D6+2, D7+1 and D8) but not exchanged between groups, so that a different heifer was used for each transfer. Ten to twelve days after transfer, conceptuses were non-surgically collected (details in Richard et al. 2015). After flushing, each recovered conceptus was carefully rinsed in fresh PBS, the embryonic disc was dissected and fixed in 4\% paraformaldehyde, and the extra-embryonic tissues were snap-frozen and stored at $-80^{\circ} \mathrm{C}$ prior to Western blotting. As a control, we used data from previously examined embryos that had been prepared using classical ET parameters (usual unsorted D7 embryos transferred at D7) that came from an earlier study of the same IVP system (culture in groups on VERO cells, in B2 medium plus FCS; Degrelle et al. 2012). 


\section{RNA isolation, amplification and microarray hybridisation}

The microarray procedure was performed as described in Hosseini et al. (2015). Total RNA (pool of 15-20 embryos per group, in triplicate) was extracted and purified using the Arcturus PicoPure RNA Isolation Kit (Thermo Fisher Scientific), including a DNase digestion (Qiagen) on the column. The quality and concentration of the extracted RNA were analysed with a bioanalyser (Agilent Technologies). All extracted samples were of high quality, with an RNA integrity number above 8.5.

For microarray purposes, purified RNA was amplified using T7-based in vitro transcription with the RiboAmp HSPlus RNA Amplification Kit (Thermo Fisher Scientific), and labelled with Cy3 using the ULS Fluorescent Labeling Kit (Kreatech, Amsterdam, Netherlands). The labelled anti-sense RNA (aRNA) was quantified using an ND-1000 Nanodrop apparatus (Thermo Fisher Scientific). Labelled aRNAs (825 ng per replicate) were hybridised on Agilent-manufactured EmbryoGENE slides (GPL13226, Robert et al. 2011) in a one-colour design using the Gene Expression Hybridisation Kit. After $17 \mathrm{~h}$ of hybridisation at $65^{\circ} \mathrm{C}$, microarray slides were washed for $3 \mathrm{~min}$ in Gene Expression Wash Buffer 1 (room temperature), $3 \mathrm{~min}$ in Gene Expression Wash Buffer $2\left(42^{\circ} \mathrm{C}\right), 10 \mathrm{~s}$ in $100 \%$ acetonitrile (room temperature) and $30 \mathrm{~s}$ in Stabilisation and Drying Solution (Agilent) at room temperature. Slides were scanned with a PowerScanner (Tecan, Männedorf, Switzerland) and feature extraction was performed with Array-pro 6.3 (Media Cybernetics, Rockville, MD, USA). The expression dataset (or GSE) is available on the GEO database (GSE96925).

\section{RNA extraction, reverse transcription and real-time PCR}

Total RNA was extracted from batches of embryos (pools of 25-45 embryos per group, in triplicate) using the Arcturus PicoPure RNA extraction kit (Thermo Fisher Scientific). Prior to extraction, carrier RNA $(2.5 \mu \mathrm{g}$ of $16 \mathrm{~S}-28 \mathrm{~S}$ carrier per sample; Roche Diagnostics) was added to restrict RNA loss during column purification and to estimate RNA recovery after purification. A purification procedure was performed, using DNAse I (Qiagen) treatment at $25^{\circ} \mathrm{C}$ for $15 \mathrm{~min}$, prior to elution. cDNAs were synthesised from total isolated RNA using the Superscript III enzyme (Invitrogen) and hexamer random primers (Roche Diagnostics) in $20 \mu \mathrm{L}$ final volume, following the manufacturer's instructions. Quantitative realtime PCR (qPCR) was carried out with SYBR Green Master Mix (Applied Biosystems) and the Step One Plus system (Applied Biosystems). Three technical replicates were performed for each sample and a standard curve protocol was used to evaluate gene expression. Reactions were performed using the equivalent of 0.01 and 0.5 embryos of cDNA per well in 96-well plates, depending upon the gene of interest. Primer sequences are provided in Supplementary Table 1 (see section on supplementary data given at the end of this article). To assess the amplification of the correct cDNA fragments, each amplicon was sequenced and BLASTed against the NCBI RNA bovine database (RefSeq Release 70). For each gene of interest, relative expression was normalised to the expression of three housekeeping genes (GAPDH, YWHAZ and SDHA) using qBasePLUS 2 software (Biogazelle, Gent, Belgium; Peynot et al. 2015).

\section{Western blotting}

Total proteins of D18 extra-embryonic tissues were prepared using RIPA buffer as previously described (Hue et al. 2015). Protein samples $(30 \mu \mathrm{g})$ were resolved by SDS-PAGE and immunoblotted with antibodies to IFN-tau (kindly provided by M. Guillomot, INRA, UMR BDR, France; diluted 500-fold), $\beta$-ACTIN $(0.4 \mu \mathrm{g} / \mathrm{mL}$, Santa-Cruz), CDX2 $(0.5 \mu \mathrm{g} / \mathrm{mL}, \mathrm{H} 43$, Santa-Cruz), ETS2 $(0.5 \mu \mathrm{g} / \mathrm{mL}, \mathrm{C} 20$, Santa-Cruz) and AP-1/cJUN $(0.5 \mu \mathrm{g} / \mathrm{mL}$, sc-45X, Santa-Cruz). After incubation with the appropriate Alexa Fluor-conjugated secondary antibody (680 or 790 conjugate, Molecular Probes), blots were revealed using the Odyssey infrared fluorescent system (Li-Cor), and the amount of each protein was determined. Signal intensity was quantified using Image software $(\mathrm{NIH})$. The arbitrary pixel densities of each protein were standardised to $\beta$-ACTIN levels and normalised to the in vivo control. Measurements were made in triplicate $(n=3)$. The data are expressed as the mean \pm S.D. Statistical analysis (t-test) was performed using GraphPad Prism 6 software. Results were considered significant if the $P$ value was $<0.05\left(^{*}\right),<0.01\left(^{* *}\right)$, or $<0.001\left(^{* * *}\right)$.

\section{Microarray analysis}

To provide context for the data generated in this study from the IVP groups $(n=6)$, our analysis included a molecular dataset from an in vivo control. The microarray data from Gad et al. (2012a) were obtained by the same person as in the current study, using the same slides (Robert et al. 2011), within the EmbryoGENE framework (bovine microarray platform; GPL13226). Only the probes $(n=43,795)$ that were common to the seven groups (D6, D6+1, D7, D6+2, D7+1, D8, in vivo D7) and 21 samples (three biological replicates per group) were analysed. Statistical analyses of microarray data were performed with BioConductor version 3.2 (Gentleman et al. 2004) and R version 3.2.4 (R Core Team 2016). A comprehensive examination of expression patterns was performed by principal components analysis (PCA) and between-class analysis (BCA), using the R package ade4 (Dray \& Dufour 2007). A betweenclass principal components analysis focuses on betweengroup variability by performing a PCA on group means. The importance of the difference between groups is assessed using the ratio of the between-group inertia to the total inertia. The statistical significance of differences between groups is then checked with a Monte-Carlo permutation test. To identify probes that were differentially expressed, the data were analysed using the package Limma (Smyth 2005), based on a linear mixed-model approach. For each Limma comparison, t-tests were performed. A Benjamini-Hochberg correction for multiple testing (Benjamini 1995) was applied and an adjusted $P$ value cut-off at 0.05 was applied.

\section{Gene Set Enrichment Analysis}

The whole expression dataset was analysed using the Gene Set Enrichment Analysis (GSEA) database (hallmark v6.1; 
Broad Institute; Subramanian et al. 2005) as well as with 17 additional gene sets. Two were downloaded from the Amigo web site (bovine metabolic sensors and stress sensors) while the remaining 15 were collected from published supplementary data; these included relevant gene sets such as those devoted to bovine cell lineage descriptors (from whole tissues (inner cell mass and trophectoderm) in vivo and in vitro (Ozawa et al. 2012, Nagatomo et al. 2013, Hosseini et al. 2015, Zhao et al. 2016) or single cells (epiblast, trophectoderm and hypoblast; Negrón-Pérez et al. 2017, Wei et al. 2017), bovine markers of embryonic quality (Cagnone \& Sirard 2016) or of in vitro culture with FCS (at 5\%; Heras et al. 2016)), expression modules of mouse embryonic lineages in diapause or WT (E2.5 to E5.5; Boroviak et al. 2015) and conserved FOXO target genes (Webb et al. 2016). The parameters we used were FDR $<5 \%, 1000$ permutations (on gene sets instead of phenotypes), use of the median value of probes (instead of the maximum) and gene set with a minimum size of 30 , instead of the default size of 15 . In doing so, 20,393 (out of 27,607) expressed IDs were considered and processed.

\section{Ingenuity pathway analysis}

To identify biological functions as well as the putative upstream regulators affected in the different groups of blastocysts, differentially expressed (DE) probes with an adjusted $P$ value $<0.05$ were selected. The significant DE probes with an annotated gene symbol were then analysed with ingenuity pathway analysis (IPA; build version 470319M, content version 43605602; Ingenuity Systems, Mountain View, CA; USA).

\section{Whole-mount in situ hybridisation}

Isolated embryonic discs that were dissected out from D18 conceptuses $(n=17)$ were fixed in $4 \%$ paraformaldehyde, stored and hybridised with a DIG-labelled Brachyury riboprobe as described by Hue et al. (2013). The hybridised embryos were mounted in Mowiol and photographed with a Coolsnap camera (Photometrics).

\section{Results}

\section{Patterns of commonly enriched genes and developmental functions confirmed the three main embryo phenotypes: fully formed blastocysts, additional day in vitro and equal culture period}

Once profiled on the EmbryoGENE platform, we searched for enriched features that could identify common signatures across IVP groups using GSEA. Using the hallmark database from the Broad Institute (v6.1) and a homemade one that included 17 relevant datasets (detailed in the 'Materials and methods' section), we identified 17 molecular features that characterised the six in vitro-produced embryonic pools (Supplementary Tables 2, 3, 4 and 5).

At first glance, the enrichment of a core of eight shared functions (in bold, Supplementary Tables 2, 3, 4 and 5) supported the existence of a universal 'in vitro' phenotype (apoptosis, cholesterol homeostasis, embryonic quality, mTORC1 and P53 signalling, Myc targets, Oxphos, whole TE). However, at the gene level, patterns of enrichment (Fig. 2 and Supplementary Table 6) provided evidence for three additional phenotypes: (i) fully formed blastocysts (D6, D7, D8; 34 genes and 3 functions in common: mTORC1, Oxphos, TE), (ii) same total culture period of 8 days (D6+2, D7+1, D8; 82 genes and 4 functions in common: Glycolysis, Oxphos, Ros, TE) and (iii) one extra day in culture for blastocyst formation at D6 or D7 (D6+1, D7+1; 87 genes and four functions in common: Apoptosis, mTORC1, P53, TE).

With respect to the expression of bovine metabolic sensors, all in vitro groups segregated to the upper expression limit set by the in vivo control; one-third

\section{D6 vs $\underline{\mathrm{D} 7}$}

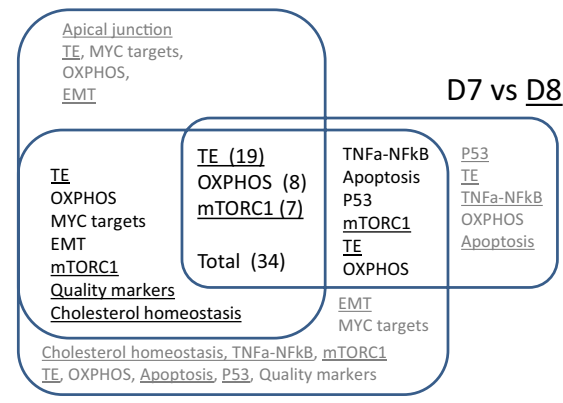

$\mathrm{D} 6+2$ vs $\underline{\mathrm{D} 8}$

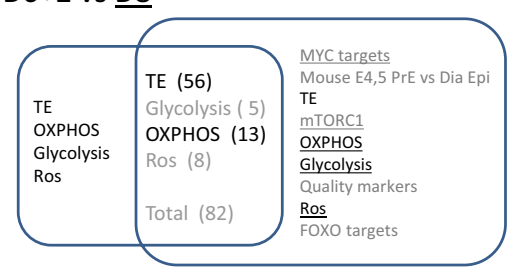

D6 vs $\underline{\mathrm{D} 8}$

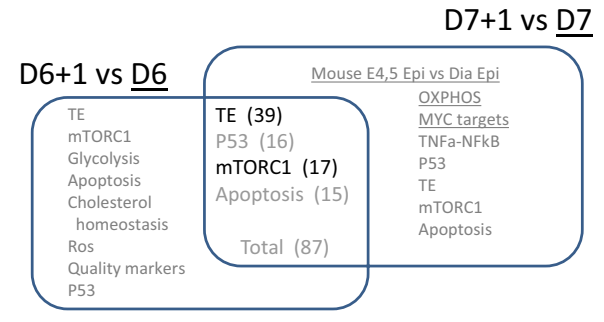

Figure 2 Common gene enrichment sets across IVP transcriptomes. GSEA identified enriched genes and functions for every paired comparison within the experimental design ( 9 pairs; Supplementary Tables 2, 3, 4 and 5). A search for shared genes and functions across these comparisons identified three clusters of 2-3 pairs: (D6 vs D7; D7 vs D8; D6 vs D8), (D6+2 vs D8; D6+2 vs D7+1) and (D6+1 vs D6; D7+1 vs D7). Each cluster was characterised by $2-3$ shared functions, but these did not necessarily involve the identical genes in each group. The enriched functions in each subset also tended to be predominantly found in the trophectoderm cells (TE) of the embryos, though, again, not with exactly the same genes (Supplementary Table 7 and the corresponding gene lists will be provided on request). In brackets are the numbers of unique gene IDs. 
of these probes represented both metabolic and stress sensors (Supplementary Table 7). This feature - absent from intra-IVP analyses, as all IVP groups expressed these genes faintly compared to the in vivo group - underlined a unique difference in micro-environment sensing between in vitro- and in vivo-produced blastocysts.

\section{Molecular differences among groups with respect to early vs late blastocyst formation and equal time in culture vs without extra time in culture}

Using a few shared functions (8 out of the 17 initially identified) and small sets of commonly enriched genes (100, at most), we examined the differences between the groups of embryos (IVP: $n=6$; in vivo, $n=1$ ). Using a PCA of all samples (seven groups, three replicates per group; Supplementary Fig. 1), we were able to distinguish the in vivo embryos (D7, Gad et al. 2012a) from all the IVPs (D6, D6+1, D7, D6+2, D7+1, D8); the D8 embryos from the D6+2 (Supplementary Fig. 1A) or D7+1 groups (Supplementary Fig. 1C) and the D6 embryos from the D7+1 (Supplementary Fig. 1B) or D6+2 groups (Supplementary Fig. 1C). However, the degree of variability among replicates within the D7, D6+1 or D7+1 groups (in the PCA) prompted us to also perform a BCA which averaged expression values for each embryo group (seven groups, Fig. 3). There too, three main axes distinguished in vivo- from in vitro-produced embryos, D6 from D6+2 (Fig. 3A and C) and D8 from D6 (Fig. 3B) or D7+1 embryos (Fig. 3C). The genes whose expression significantly contributed to these axes are represented in the violin plots in Fig. 3D by high gene scores (red tails).

These analyses thus revealed that (i) D8 and D6 blastocysts differed at a molecular level even though blastocysts in both groups were recorded as newly formed and expanded and (ii) despite being cultured for the same length of time, embryos in groups D8, D7+1 and $\mathrm{D} 6+2$ also demonstrated recognisable differences. This latter finding was less surprising, though, in view of the differences in developmental status between these groups, i.e. expanded (D8) vs hatched (D7+1, D6+2). In this context, the gene enrichment patterns (Fig. 2) that were shared among the extended-culture groups (D6+1-D7+1: Fig. 3A, B and C; D6+2-D6+1: Fig. 3B and $\mathrm{C}$ ) supported the hypothesis that an extra day in culture generated similar adaptations in both D6 and D7 blastocysts.

\section{Differential gene expression highlighted a major distinction between in vivo- and in vitro-produced embryos}

As was observed with GSEA and BCA, patterns of gene expression in in vitro-produced embryos were different from those that developed in vivo. Specifically, more than 15,000 probes (corresponding to 6746 genes) were $\mathrm{DE}$, equally distributed between
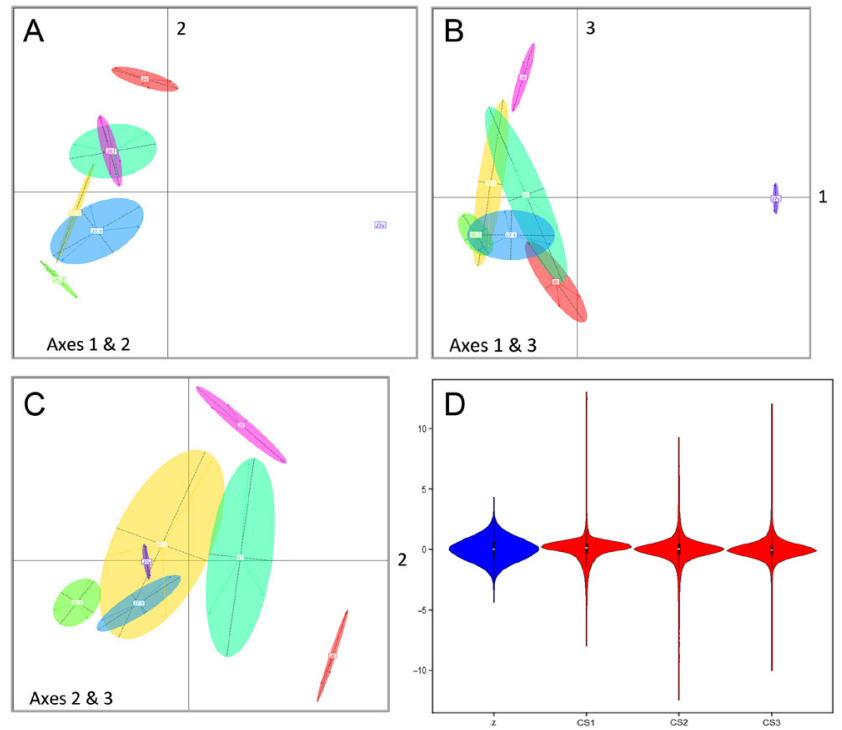

Figure 3 Molecular differences between in vitro and in vivo transcriptomes. Between-class analysis (BCA) on all groups of blastocysts, experimental and control (in vitro, $n=6$; in vivo, $n=1$ ). In A to $C$, projections based on expression values of a subset of probes that were shared among all groups, averaged on a per-group basis, along three main axes (1-3). In red, green and pink: the D6, D7 and D8 blastocysts. In yellow, blue and light green: the D6+1, D7+1 and D6+2 embryo groups. In D, the violin plots illustrate the gene scores along a normal distribution (in blue) or along each of the axes of the BCA (in red). Long distribution tails are indicative of high gene scores (or high contributions to the axis).

over- and under-expression (Table 1). In addition, $60-70 \%$ of the expression differences among IVPs were part of the 'vivo/vitro' contrast, so that in two of the intraIVP contrasts (D6 vs D8 and D8 vs D6+2) the contrastspecific differences were quite small (reduced to 53 and 23 genes, respectively). However, the comparison between D6 and D6+2 revealed a much higher number of differentially expressed genes (DEGs; $n=237 ; 4$ and 10 times more than D8 vs D6 and D8 vs D6+2, respectively; Supplementary Table 8$)$. D6+1, D7 and D7+1 were included in the analysis and in the 'all IVP' group, but are not presented in Table 1 due to the fact that the paired contrasts involving these groups yielded limited numbers of contrast-specific DEGs $(<15)$, with most being shared with the vivo/vitro contrast and the other contrasts presented here.

By performing an IPA, we found that these DEGs (Table 2) played a part in metabolic, developmental and cellular functions that were shared among either in vitro-produced (lipid metabolism, cell morphology) or in vivo-developed blastocysts (amino acid metabolism, cellular movement, gene expression). DEGs that were putative upstream regulators encoded 22 transcriptional regulators (CDX2, CDKN2A, CITED2, GATA4, HDAC6, HSF1, ID2, ID3, MECP2, MYC, MYCN, NANOG, NCOA1, PDX1, PML, POU5F1, RB1, STAT3, TFAP2A, TP53, WT1, YY1), four ligand-dependent nuclear 
Table 1 Differential gene expression between in vitro-produced blastocysts that formed at D6 or D8 or were isolated at D6 and cultured two more days (D6+2).

\begin{tabular}{lcccc}
\hline & \multicolumn{3}{c}{ Contrasts } \\
\cline { 2 - 5 } & D6+2 (vs D6) & D8 (vs D6) & D8 (vs D6+2) & D7 in vivo vs all IVP* \\
\hline Adjusted $P$ value $<0.05$ & $6.2-6<0: 322$ & $8-6<0: 92$ & $8-6.2<0: 82$ & in vivo-IVP<0: 7102 \\
& $6.2-6>0: 864$ & $8-6>0: 234$ & $8-6.2>0: 56$ & in vivo-IVP>0: 8691 \\
DE probes & 1186 & 326 & 138 & 15,793 \\
Annotated DE probes & 778 & 196 & 64 & 8001 \\
Unique DE IDs (or DEGs) & $\mathbf{7 0 2}$ & $\mathbf{1 8 8}$ & $\mathbf{6 4}$ & $\mathbf{6 7 4 6}$ \\
(in vivo-all IVP) shared genes & $\mathbf{4 6 5}(\mathbf{6 6} \%)$ & $\mathbf{1 3 5}(\mathbf{7 2} \%)$ & $\mathbf{4 1}(\mathbf{6 4} \%)$ & $\mathbf{5 2 4}$ \\
Contrast-specific DE genes & $237(34 \%)$ & $53(28 \%)$ & $23(34 \%)$ & 6222 \\
Shared DEGs among IVPs & 46 & 40 & 19 & \\
\hline
\end{tabular}

*Transcriptomes were obtained from six experimental groups of bovine blastocysts, but three (D7, D6+1 and D7+1) do not appear here in any paired contrast due to the limited number of differentially expressed genes that characterised them. However, all six groups (D6, D6+1, D7, $\mathrm{D} 7+1, \mathrm{D} 8, \mathrm{D} 6+2$ ) were combined to form the 'all IVP' group which was compared to in vivo D7 development. The in vivo controls which originated from a previous study that used the same array platform within the EmbryoGENE network (Gad et al. 2012a). The numbers of differentially expressed probes/genes are indicated if they were significant at an adjusted $P$ value of $<0.05$.

receptors (ESR1, NR1H2, NR1H3, NR1H4) and one enzyme (DNMT3B). Only a few DEGs were initially identified through gene set enrichment (166 in D6+2 vs D6, 45 in D8 vs D6, 6 in D8 vs D6+2), among which were four putative regulators identified within the first contrast (ID2, MYC, STA3, TFAP2A, D6+2 vs D6).

Across all group contrasts, eight genes were selected for further validation with RT-qPCR, using three independent biological replicates per condition (D6, D6+2, D8). The genes were expressed across different cell lineages (AKR1A1, DNMT3A, FADS3, PTCS2 in TE; APOA 1, DNMT3A, STAT3 in PrE; NANOG in ICM), two were identified as regulators (NANOG in D6+2 and D8, STAT3 in D6; Table 2) and one appeared in only one contrast (PTGES2 in D8 vs D6). The results for the genes that had demonstrated differential expression (log ratios) below $1.3(0.6,0.9$, and 1.2) were not corroborated with RT-qPCR. However, APOA1, NANOG and PTCS2 (expression log ratios of 1.7-2.5) were indeed found to be more expressed in D6+2 than in D6 or D8 embryos (Fig. 4). Here, the RT-qPCR analysis did not validate the changes in expression found for AKR1A1, FADS3, PTGES2 and STAT3, but a meta-analysis including 20 studies within the EmbryoGENE network also reported that the expression levels of these genes were affected by culture and/or culture conditions, as were those of the 18 DEGs identified here as putative regulators (Gad et al. 2012a, Plourde et al. 2012b, Khan et al. 2016; Fig. 5).

\section{ET revealed two phenotypes: embryos that survived to D18 and a subset that produced IFN-tau at levels similar to controls}

Before transfer, the IVP embryos from the D6, D6+2, $\mathrm{D} 7+1$ or D8 groups were similar in some ways but distinct in others (see results above of GSEA, BCA and DEG analysis). Moreover, an analysis of negative pregnancy predictors in these groups was inconclusive; these predictors had been previously established using biopsied in vitro-produced embryos and are associated with the inability to reach term (no calf, no pregnancy, embryonic resorption: El-Sayed et al. 2006, Ghanem et al. 2011). Specifically, D6 and D6+2 blastocysts expressed similar numbers of negative pregnancy predictors (five vs six DEGs), while D8 blastocysts did not express any of those genes as DEGs, and the $\mathrm{D} 7+1$ group only expressed two (Table 2, D7+1 not shown). Four groups of IVP embryos were then transferred to recipient heifers at either D6 (D6 group) or D8 (D6+2, D7+1, D8) and recovered at D18; each recipient was used for only one group of embryos. Although this aspect of the study design had drawbacks (specifically, we were unable to evaluate interactions between different embryos and recipient heifers), we still believed that the intrinsic embryo viability would be at least partly mirrored by the post-transfer phenotypes (Fig. 6). The uterine fluids, which serve as in vivo modulators of embryonic viability, were not evaluated in the current work (Fig. 1). All conceptuses were elongated (17/17; Fig. 6A) and most displayed a gastrulation landmark (such as a primitive streak, 13/17). The expression of a mesoderm marker gene (TBXT mRNA) was detected at early-, mid-, or lateprimitive streak stages $(\mathrm{HH} 3-\mathrm{HH} 5,13 / 17$; Fig. 6B) and even in the youngest stage $(\mathrm{HH} 2 ; 4 / 17)$, which exhibited a posterior pole containing a small TBXT domain but no visible streak (not shown). The most frequent stage observed in the IVP embryos at D18 was stage 3 (or mid-streak: 10/17) regardless of group designation (D6T6, D6+2-T8, D7+1-T8, D8-T8, IVP control (D7-T7)); this was slightly delayed in comparison to embryos that developed entirely in vivo, which by D18 had mostly reached stage $4(7 / 10)$. All conceptuses produced IFNT protein, either at an equal level to (D6 and D7+1) or at higher levels (4-9 times more in the D8 and D6+2 embryos, respectively; Fig. 6C) than control embryos that were developed entirely in vivo to D18. However, CDX2, ETS2 and JUN proteins were undetectable at D18. In comparison, IFNT mRNA levels in the pretransfer embryos were 2.4 and 3.6 times higher in D8 
Table 2 Functions and regulators associated with the differential expression among in vitro-produced blastocysts that formed at D6 or D8, or that were isolated at D6 and cultured two more days (D6+2).

\begin{tabular}{|c|c|c|c|c|}
\hline & \multicolumn{4}{|c|}{ Comparisons } \\
\hline & D6+2 (vs $\underline{\mathrm{D}}$ ) & D8 (vs D6) & D8 (vs D6+2) & D7 vivo (vs all IVP : $6,6+1,7,7+1,8,6+2$ ) \\
\hline \multirow{6}{*}{$\begin{array}{l}\text { Molecular and cellular } \\
\text { functions (on the total } \\
\text { numbers of DEG) }\end{array}$} & Cellular movement & Cellular movement & Cell morphology & Cellular movement \\
\hline & Metabolic disease & Cellular compromise & Gene expression & RNA post-transcriptional modification \\
\hline & Amino acid metabolism & Lipid metabolism & Lipid metabolism & Protein trafficking \\
\hline & Carbohydrate metabolism & & Molecular transport & Gene expression \\
\hline & Lipid metabolism & & & Protein synthesis \\
\hline & Cell morphology & & & Amino acid metabolism \\
\hline \multicolumn{5}{|l|}{ Upstream regulators } \\
\hline In silico identified & CITED2 $(-1.08 / 7 / 2.4)$ & $\underline{\text { GATA4 }}(-2.3 / 6 / \mathbf{1 . 7})$ & DNMT3B $(-1 / 3)$ & $\underline{\text { DNMT3B }}(-1.8 / 6 /-2.2)$ \\
\hline $\begin{array}{l}\text { Differentially } \\
\text { expressed in the } \\
\text { dataset } \\
\text { (ExprLogRatio) }\end{array}$ & $\underline{\text { POU5F1 }}(-0.98 / 23 /-\mathbf{0 . 4 5})$ & MECP2 (2/4) & & $\underline{N R 1 H 3}(-1.5 / 12 /-2.2)$ \\
\hline $\begin{array}{l}\text { Target molecules in } \\
\text { the dataset }\end{array}$ & $\underline{\text { STAT3 }}(-0.96 / 30 /-\mathbf{0 . 7})$ & NANOG $(1.8 / 4)$ & & $\underline{\operatorname{TP53}}(-1.4 / 100 /-3.2)$ \\
\hline \multirow[t]{14}{*}{ IPA activation Z-score } & $\underline{H D A C 6}(-0.83 / 5 / \mathbf{0 . 9})$ & & & $\underline{Y Y 1}(-1.1 / 20 /-\mathbf{1 . 1})$ \\
\hline & $\overline{C D X 2}(0.75 / 8 / \mathbf{1 . 5})$ & & & $\overline{M Y C N}(-0.8 / 38 /-3.3)$ \\
\hline & DNMT3B $(0.97 / 11 /-\mathbf{0 . 3})$ & & & $\overline{N R 1 H 2}(-0.6 / 8 /-1.1)$ \\
\hline & ID2 $(1.92 / 10 / \mathbf{1})$ & & & $\overline{\mathrm{NR} 1 \mathrm{H} 4}(-0.6 / 11 / \mathbf{0 . 4})$ \\
\hline & MYC $(2.07 / 78 / \mathbf{3 . 1})$ & & & $\underline{I D 3}(-0.6 / 6 / 2.2)$ \\
\hline & NANOG $(2.55 / 9 /-\mathbf{0 . 5})$ & & & $\overline{\text { HSF1 }}(-0.3 / 11 /-2.2)$ \\
\hline & TFAP2A $(2.75 / 11 /-\mathbf{0 . 3})$ & & & $\overline{\operatorname{ESR1}}(0.3 / 92 / \mathbf{2 . 2})$ \\
\hline & & & & WT1 $(0.4 / 19 / \mathbf{0 . 2})$ \\
\hline & & & & $P M L(0.4 / 13 / 2.2)$ \\
\hline & & & & CDKN2A $(0.4 / 21 / \mathbf{- 1 . 7})$ \\
\hline & & & & RB1 $(0.6 / 25 /-3.1)$ \\
\hline & & & & PDX1 $(0.6 / 11 /-\mathbf{0 . 0 8})$ \\
\hline & & & & TFAP2A $(0.8 / 8 / \mathbf{0 . 1})$ \\
\hline & & & & NCOA1 (1.2/6/-2) \\
\hline $\begin{array}{l}\text { Genes selected for } \\
\text { validation }\end{array}$ & $\begin{array}{l}\text { AKR1A1, APOA1, } \\
\text { DNMT3A, FADS3, } \\
\text { NANOG, PTGS2, STAT3 }\end{array}$ & $\begin{array}{l}\text { APOA1, NANOG, } \\
\text { PTGES2 }\end{array}$ & $\underline{F A D S 3}$ & $\underline{D N M T 3 A}, \underline{F A D S 3}$ \\
\hline \multirow{2}{*}{$\begin{array}{l}\text { Negative pregnancy } \\
\text { predictors (no calf, no } \\
\text { pregnancy, embryonic } \\
\text { resorption) }\end{array}$} & $\begin{array}{l}\text { AKR1B1, CSRP2, ELOVL1, } \\
\text { LGALS3, PRSS23, S100A10 }\end{array}$ & $\underline{P L A U}$ & PRSS23 & $\begin{array}{l}\text { ACTG1, CEP164, DDX5, DSTN, EEF1A1, } \\
\text { MLH1, MRPL33, ODC1, PLAU, RIOK3, } \\
\text { RPLPO, TPT1, TUBA1C }\end{array}$ \\
\hline & 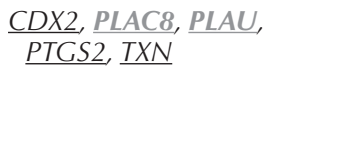 & & & 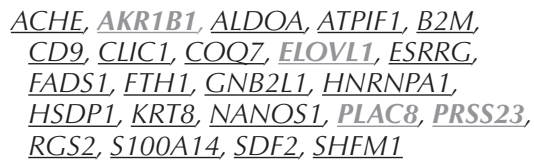 \\
\hline
\end{tabular}

Three to six functions were identified per contrast that were unique to the contrast, shared among IVP groups (in bold and in black), or shared with the 'vivo-vitro' contrast (in bold and in grey). Many upstream regulators were identified. Shown are those that were differentially expressed (ExprLogRatio) and whose target molecules were also in the dataset (Target number). Activation scores are provided as calculated by IPA (Z-scores, in bold): (+) indicates activation, (-) indicates inhibition. Each putative regulator is therefore described by three features: (ExprLogRatio/Target number/Z-score). The underlined genes are those whose expression increased in the underlined group of the contrast. As depicted for the functions, the regulators that are in bold and in grey are those that were shared with the 'vivo-vitro' contrast.

and D6+2 blastocysts, respectively, compared to D6 levels (array data confirmed by RT-qPCR; Fig. 7). The expression profile of IFNT mRNA was similar to that of UN, whereas ETS2 and CDX2 levels appeared to be either similar in all groups (D6, D6+2, D8: ETS2) or to demonstrate patterns opposite to those of IFNT and JUN (similar in D6+2 and D6 embryos, lower in D8: CDX2; Fig. 7). Recovery rates were quite similar between D6 and T6 (58\%) and controls (unsorted D7-T7 blastocysts or full in vivo development: $62 \%$ and $66 \%$, respectively), but generally lower in the D6+2-T8, D7+1-T8 or D8-T8 groups (33-25\%).

\section{Discussion}

Although there is abundant literature that has questioned the ability of in vitro-produced embryos to replicate the development of those produced in vivo, in the current study, all conceptuses in the experimental groups that survived up to D18 gastrulated and elongated almost as well as in vivo (D18) or in vitro controls (classical D7/T7). Two other notable results of this study were that the recovery rate differed markedly between D6 and D8 embryos that were immediately transferred (58 vs $25 \%$ in D6/T6 vs D8/T8), and that, 

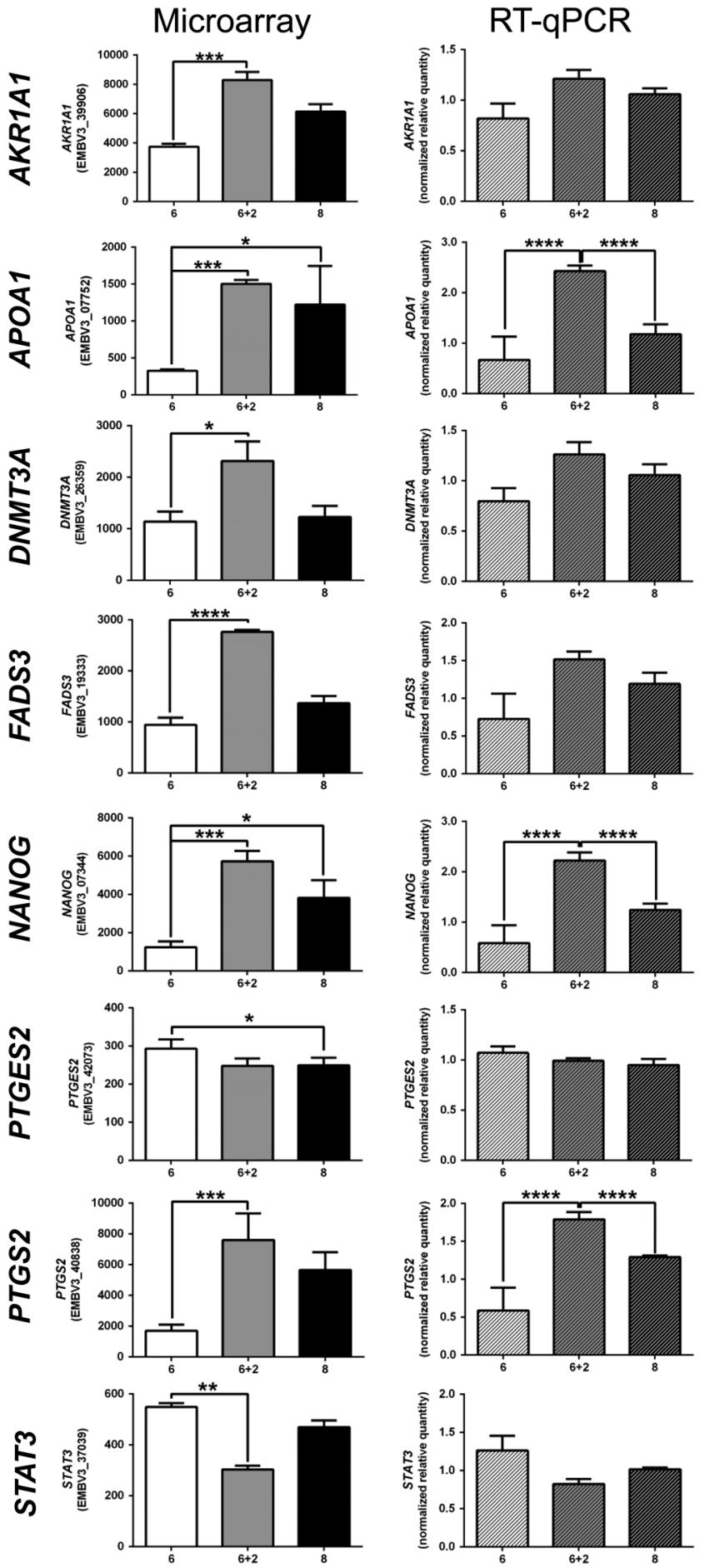

Figure 4 Gene expression differences $(n=8)$ observed in microarrays (left panel) and RT-qPCRs (right panel). RT-qPCR data were normalised by qBasePLUS based on GAPDH, YWHAZ and SDHA expression. Significant differences are indicated by stars: $\left(^{*}\right)$ for a $P$ value $<0.05,(* *)$ for a $P$ value $<0.01,(* * *)$ for a $P$ value $<0.001$ and $(* * * *)$ for a $P$ value $<0.0001$. PCR primers are provided in Supplementary Table 1. despite a mortality of $40-60 \%$ in the 2 weeks following $\mathrm{ET}$, no signature of dying or surviving was detectable in any of the transferred groups (D6, D6+2, D7+1, D8). Finally, we were intrigued by our finding of a ' +1 ' phenotype in the D6+1 and D7+1 embryos: these groups overlapped in the BCA and shared a larger gene set than day 6 and day 7 blastocysts did, which could be a possible sign of a similar adaptation to the in vitro environment.

Due to the limited size of the dataset (48 embryos transferred; 14 recovered) and the non-physiological use of the recipient uteri (six embryos each instead of one), our data do have limits. However, the broad patterns apparent in our analyses are worthy of further discussion and investigation. Generally speaking, few D7+1 and D8 embryos survived in utero (25\%), while those in the D6+2 and D6 groups fared better (33 and $58 \%$, respectively). It is worth noting that the $58 \%$ survival rate observed for this last group was not far from the recovery rate that we had previously reported for D7 embryos produced and transferred under the very same conditions (Degrelle et al. 2012). The D6-T6 experimental group (expanded blastocysts formed at D6 and immediately transferred) was also similar to the IVP control group (D7-T7) in terms of the number of embryonic tissues that reached stage $3(4 / 7)$ and the amount of IFNT that was produced by elongated tissues. In the other three experimental groups, elongation and gastrulation patterns were also identical to controls (10/10 filamentous; $5 / 7$ at stage $\mathrm{HH} 3$ ), which was inconsistent with previous reports that described shorter conceptuses and smaller embryonic discs at D16 (after transfer of D7 IVP blastocysts cultured in SOF plus BOEC; Bertolini et al. 2002) or no disc at D14 after culture in KSOM or SOF (Fischer-Brown et al. 2004, Berg et al. 2010). There was a substantial increase in the amount of IFNT produced by the elongated tissues of the D8-T8 and D6+2-T8 groups compared to D6-T6 embryos ( $\times 4$ and $\times 9$, respectively), which we could not relate to the expression of CDX2, ETS2 or JUN proteins (Sakurai et al. 2013) since none of these transcription factors was detectable in these conditions. In this, our results differed from those reported by Xavier et al. (1997) for the very same antibodies, which perhaps could be attributable to differences in the protein extraction buffers or the revealing methods used. Our Western blot results for IFNT were mimicked in the amount of IFNT transcript detected prior to transfer in the D8 and D6+2 blastocysts $(\times 2.4$ and $\times 3.6$ compared to D6). Interestingly, the profile of IFNT mRNA was similar to that of JUN, whereas those of CDX2 and ETS2 differed. Earlier studies within the EmbryoGENE network likewise reported that IFNT and IUN expressions were similarly affected by culture conditions that included 


\begin{tabular}{|c|c|c|}
\hline \multicolumn{2}{|c|}{$\begin{array}{c}\text { Whole EmbryoGENE } \\
\text { dataset meta-analysis }\end{array}$} & D6+2-D8-D6 \\
\hline $\begin{array}{c}\text { Impact of } \\
\text { culture }\end{array}$ & $\begin{array}{c}\text { Culture } \\
\text { Conditions }\end{array}$ & $\begin{array}{c}\text { Current } \\
\text { DEG }\end{array}$ \\
\hline $\begin{array}{c}\text { Adjusted P- } \\
\text { Value }\end{array}$ & $\begin{array}{c}\text { Adjusted P- } \\
\text { Value }\end{array}$ & Gene \\
\hline 1.60 e-10 & 0.0735 & AKR1A1 \\
\hline 5.24 e-06 & 3.67 e-05 & APOA1 \\
\hline 0.0653 & 0.1665 & DNMT3A \\
\hline 0.0032 & 0.0003 & FADS3 \\
\hline 2.06 e-14 & 0.0972 & NANOG \\
\hline 0.5911 & 0.0007 & PTGES2 \\
\hline 0.0138 & 0.0012 & PTGS2 \\
\hline 7.98 e-05 & 0.1243 & STAT3 \\
\hline
\end{tabular}

\begin{tabular}{|c|c|c|}
\hline \multirow{2}{*}{$\begin{array}{c}\text { Whole EmbryoGENE } \\
\text { dataset meta-analysis }\end{array}$} & D6+2-D8-D6 \\
\hline Impact of & Culture & Current \\
\cline { 3 - 3 } & Conditions & $\begin{array}{c}\text { upstream } \\
\text { regulators }\end{array}$ \\
\hline $\begin{array}{c}\text { Adjusted P- } \\
\text { Value }\end{array}$ & $\begin{array}{c}\text { Adjusted P- } \\
\text { Value }\end{array}$ & Gene \\
\hline 0.1503 & 0.0717 & CDX2 \\
\hline 0.0029 & $2.42 \mathrm{e}-05$ & CDKN2A \\
\hline $5.58 \mathrm{e}-10$ & $4.37 \mathrm{e}-06$ & CITED2 \\
\hline 0.9204 & 0.0827 & DNMT3B \\
\hline 0.2705 & $7.55 \mathrm{e}-05$ & ESR1 \\
\hline 0.0095 & 0.0774 & GATA4 \\
\hline 0.3249 & 0.7057 & HDAC6 \\
\hline 0.5609 & $2.10 \mathrm{e}-05$ & HSF1 \\
\hline 0.0008 & 0.1461 & ID2 \\
\hline $4.73 \mathrm{e}-08$ & $2.27 \mathrm{e}-06$ & ID3 \\
\hline 0.0003 & 0.0004 & MECP2 \\
\hline $4.10 \mathrm{e}-06$ & 0.1461 & MYC \\
\hline 0.6067 & 0.2033 & MYCN \\
\hline $9.04 \mathrm{e}-07$ & 0.0002 & NCOA1 \\
\hline 0.0001 & 0.4639 & NR1H2 \\
\hline 0.0408 & 0.1985 & NR1H3 \\
\hline 0.5722 & 0.0028 & NR1H4 \\
\hline 0.1204 & 0.1204 & $P D X 1$ \\
\hline 0.3156 & $7.74 \mathrm{e}-05$ & $P M L$ \\
\hline $3.47 \mathrm{e}-12$ & 0.0001 & $P O U 5 F 1$ \\
\hline 0.0041 & 0.0678 & $R B 1$ \\
\hline 0.2940 & 0.0002 & TFAP2A \\
\hline 0.2040 & 0.3827 & TP53 \\
\hline 0.7309 & 0.0092 & WT1 \\
\hline 0.0131 & 0.0013 & YY1 \\
\hline
\end{tabular}

Figure 5 Effect of in vitro culture or culture conditions on the expression of certain DEGs as recorded by studies within the EmbryoGENE network. A meta-analysis of the entire dataset from the EmbryoGENE network was used to investigate the differential expression of certain DEGs identified herein. Presented are the adjusted $P$ values that report the statistical relevance in studies that investigated the effects of culture conditions (SOF, CO-culture in B2-BRL), origin of the oocytes (culture post ovum pick-up) and full or partial vitro vs full or partial vivo development (including the D7 control that was used herein: full vivo; Gad et al. 2012a). Among these DEGs are the eight that were selected for biological validation with qRT-PCR (in A), and the 27 that were identified as putative upstream regulators in the current dataset (in B). Note that: (i) the putative regulators encoding NANOG and STAT3 appear only once (A panel), (ii) DNMT3A was not confirmed as a DEG either internally (current RT-qPCR) or externally (meta-analysis) and (iii) the differential patterns of CDX2, DNMT3B, HDAC6, MYCN, PDX1 and TP53 were not validated beyond the current study. Adjusted $P$ value: not validated, in grey co-culture with VERO cells in B2 medium without serum (Plourde et al. 2012a).

D6+2 and D6 embryos differed substantially in gene expression, possibly due to dysregulations resembling the epigenetic ones associated with IFNT (Sakurai et al. 2009) as well as those at other loci following in vitro production (Salilew-Wondim et al. 2015, Barrera et al. 2017). Of the embryos that could be classified as high producers of IFNT (D6+2, D8), 67-75\% died prior to D18, which was consistent with the hypothesis of Wrenzycki et al. (2001) that high-IFNT producers are blastocysts of poor quality. Even though $5.8 \%$ of the genes analysed were DE between the D6+2 and D6 transcriptomes (1186 out of 20,393 expressed probes), we were not able to detect any signatures that could point to the mechanisms responsible for death (or survival). Future work focused on individuals instead of pooled embryos, using RNA sequencing instead of microarrays, may enable such a discovery, but here, the betweengroup analysis of D6+2, D6 and D8 embryos found these groups to be relatively homogeneous in gene expression (less than $6 \%$ to less than $1 \%$ differential expression).

Of all the extended culture groups, D6+2 embryos had the highest number of DEGs with respect to the group they derived from, D6. These differences may have accumulated as a consequence of the extended stay in vitro (+2 days). Two additional observations were consistent with this hypothesis: first, many of the enriched genes shared between the D6+2 and D6 groups were also shared between the D6+1 and D6 blastocysts $(n=242)$, and second, the number of genes that were unique to each comparison was seven times greater in the former pair than in the latter (286 vs 40). Alternatively, since D6+2 embryos were hatched while D6 were only expanded, the molecular differences between the two groups may have merely resulted from ordinary developmental functions involved in the differentiation of trophectoderm, primitive endoderm or inner cell mass. Evidence to support this hypothesis was found with the observation that a great deal of the gene expression that was enriched in D6+2 embryos was from the trophectoderm tissue, while enriched gene expression in the D6 embryos tended to be in the inner cell mass. Although the enriched gene expression was not entirely specific to any of these cell lineages, none of these gene patterns was expressed in both ICM and TE (Hosseini et al. 2015). Surprisingly, the gene enrichment analysis also revealed that D6+2 embryos were much less similar to D6 embryos than they were to the other group of expanded embryos, D8-forming blastocysts (D6+2 vs D8: 10 times fewer differences than in D6+2 vs D6). Could this be due to the fact that D6+2 and D8 blastocysts each spent a total of 8 days in culture and thus shared similar adaptations to the in vitro environment? Some evidence supporting this idea came from another finding of the gene enrichment analysis that 82 genes (linked with OXPHOS, ROS and glycolysis), which 


\begin{tabular}{|c|c|c|c|c|c|c|c|c|}
\hline \multirow{2}{*}{$\begin{array}{l}\text { Experimental } \\
\text { groups }\end{array}$} & \multirow{2}{*}{$\begin{array}{l}\text { Status on day } \\
\text { of transfer }\end{array}$} & \multirow{2}{*}{$\begin{array}{l}\text { Day of transfer } \\
\text { (6 embryos per } \\
\text { transfer) }\end{array}$} & \multirow{2}{*}{$\begin{array}{l}\text { Recovery rate } \\
\text { (uterine flushing;) }\end{array}$} & \multirow{2}{*}{$\begin{array}{l}\text { Elongation } \\
\text { Status } \\
\text { (whole EET) }\end{array}$} & \multicolumn{4}{|c|}{$\begin{array}{c}\text { Frequency of } \\
\text { gastrulation HH stages }\end{array}$} \\
\hline & & & & & 2 & 3 & 4 & 5 \\
\hline D6-T6 & D6 & 6 & $7 / 12=58 \%$ & filamentous & & 4 & 1 & 2 \\
\hline $\mathrm{D} 6+2-\mathrm{T} 8$ & $\mathrm{D} 6+2$ & 8 & $4 / 12=33 \%$ & filamentous & & 2 & & 2 \\
\hline D7+1-T8 & D7+1 & 8 & $3 / 12=25 \%$ & filamentous & 2 & 1 & & \\
\hline D8-T8 & D8 & 8 & $3 / 12=25 \%$ & filamentous & & 3 & & \\
\hline $\begin{array}{c}\text { D7-T7 } \\
\text { IVP control }\end{array}$ & $\begin{array}{l}\text { Unsorted } \\
\text { D7 }\end{array}$ & 7 & $\begin{array}{c}62 \% \\
(n=10, \text { Degrelle, 2012) }\end{array}$ & filamentous & 2 & 5 & 3 & \\
\hline In vivo control & - & - & $\begin{array}{c}66 \% \\
(n=10 ; \text { Degrelle, 2012) }\end{array}$ & filamentous & & 3 & 7 & \\
\hline
\end{tabular}

B

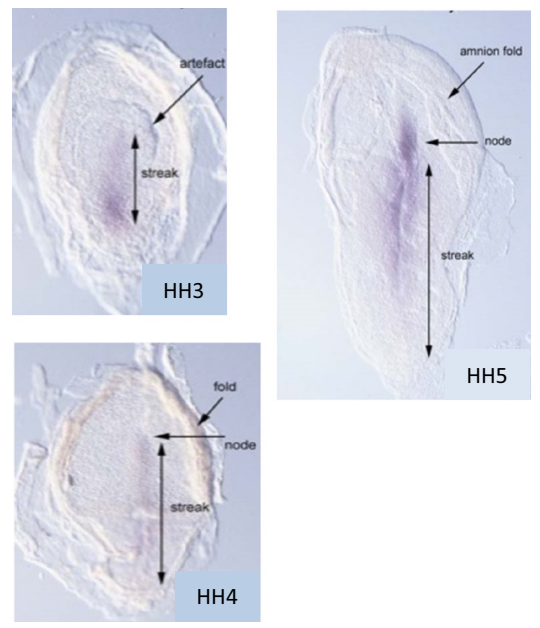

C
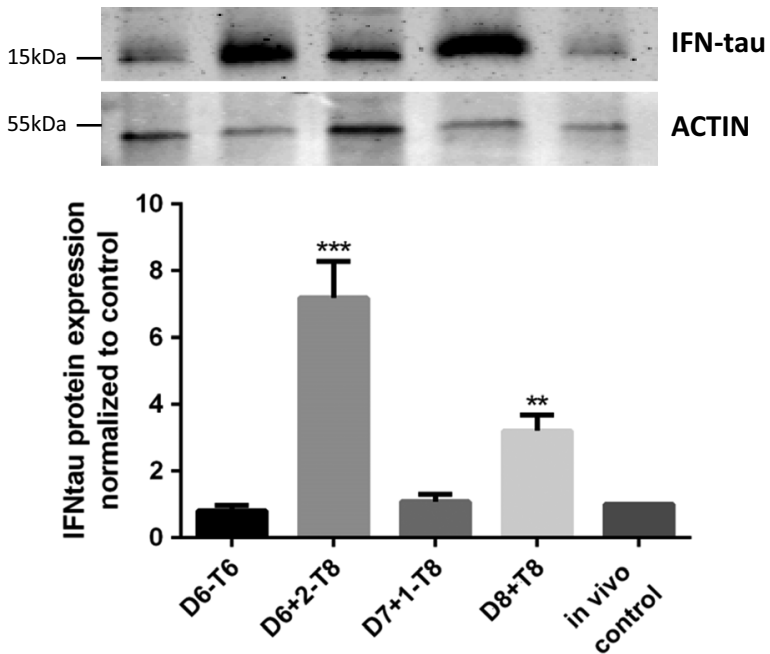

Figure 6 Post-transfer phenotypes at D18. Bovine conceptuses were collected 10-12 days after transfer of in vitro-formed blastocysts; blastocysts were fully formed at D6-D8 or maintained in culture 1 or 2 additional day(s). In (A), recovery rates are provided. With the exception of the D7+1-T8 and D8-T8 groups, recovery rates all fell within previously reported ranges for the transfer of multiple embryos (11 per transfer, $40 \%$ (Fischer-Brown et al. 2004); 3-30 per transfer, 53\% (Berg et al. 2010); 5-6 per transfer, 62\% (Degrelle et al. 2012)). Conceptus sizes were recorded and conceptuses were all identified as filamentous (length range: 108-182 mm). Embryonic discs were observed and identified as gastrulating (typical $\mathrm{HH}$ (Hamburger and Hamilton)) stages 2-5 as defined in (Hue et al. 2001). In grey, the two control datasets: from embryos which experienced full in vivo development and those that underwent classical ET at D7 (unsorted D7 IVP embryos transferred at D7). These originated from a previous study that used the identical IVP system (culture in groups, on VERO cells, and in B2 medium plus FCS;

Degrelle et al. 2012). In (B), gastrulation landmarks are indicated: streak (for primitive streak), node (for Hensen's node), and folds (for amnion folds). In situ hybridisation with a low concentration of bovine TBXT riboprobe revealed a characteristic 'violin'-shaped pattern in the embryonic tissues. In (C), IFN-tau (17 kDa) production was evaluated within the elongated tissues by Western blotting (3 biological samples per condition) and quantified relative to ACTB $(42 \mathrm{kDa})$. The control in this case was provided by the in vivo-developed embryos.

represented $58 \%$ of the shared enriched genes in the D6+2 vs D8 comparison, were also found to be enriched in D7+1 embryos (the third group that spent 8 days in culture). On the other hand, some of the differences between the D6+2 group and the D8 or D6 embryos may have originated in differences between these latter two groups: although both comprised embryos that were expanded, members of these two groups may have differed a great deal at the molecular level due to the intrinsic features that made them form blastocoels at 8 or 6 days, respectively, post fertilisation. In agreement with this were the findings that the newly formed blastocysts (D6, D7 and D8) shared the smallest enriched gene set (34 genes, representing less than $20 \%$ of the enriched genes in D7 vs D8, D6 vs D7, or D6 vs D8 comparisons) and that the D6 and D8 groups were opposed in the 

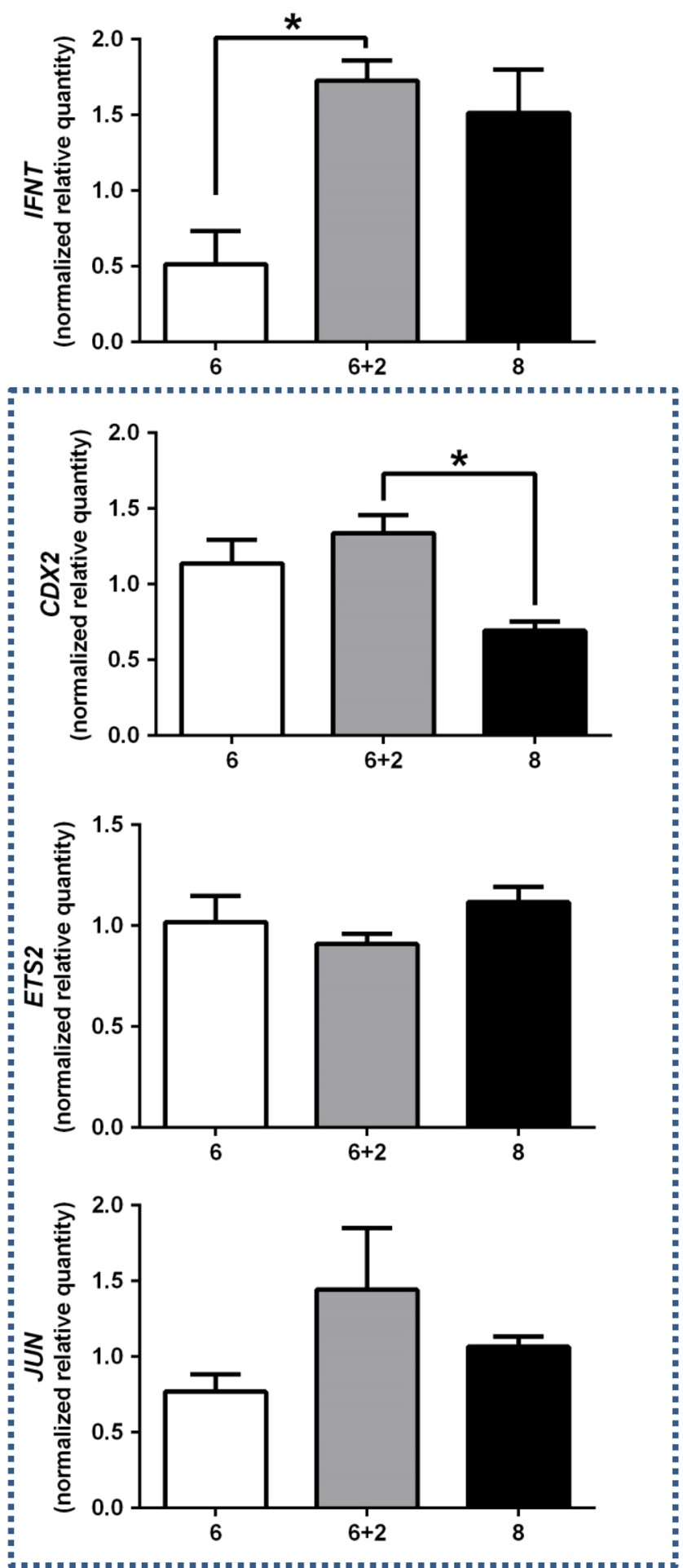

Figure 7 IFNT regulation. The expression of IFNT and its potential regulators, CDX2, ETS2 and AP-1/JUN (within the dashed lines), was analysed in the D6, D6+2 and D8 groups. RT-qPCR data were normalised by qBasePLUS based on GAPDH, YWHAZ and SDHA expression. JUN was detected and quantified at very low levels in D6 embryos, as was CDX2 in D8 embryos (lower limits of the standard curve). Significant differences are indicated by stars: $\left({ }^{*}\right)$ for a $P$ value $<0.05$. PCR primers are provided in Supplementary Table 1.
BCA along axes 1-3 and 2-3, but not 1-2. Interestingly, though, the small amount of differential gene expression between D6 and D8 embryos would seem to be evidence for similarity between the two groups. Clearly, the biological complexity of this system goes far beyond the analyses that we performed here.

Although they spent different amounts of time in culture and originated from different blastocysts, D6+1 (vs D6) and D7+1 (vs D7) embryos shared an enriched gene set of 87 genes associated with three functions (mTORC1, P53, apoptosis); together, these genes represented 26-30\% of those enrichment sets and possibly define $a$ ' +1 ' phenotype. Some of these enriched genes (33 of 87) were even shared with the D6+2 embryos (which could be considered $[\mathrm{D} 6+1]+1)$. This ' +1 ' phenotype made logical sense but it also reinforced the uniqueness of the D $6+2$ embryos, demonstrating the magnitude of the adaptive response of D6 blastocysts to an extended time in culture.

Many gene expression differences have been found between in vitro- and in vivo-produced embryos, as has often been reported in the literature (Gad et al. 2012b). The majority of these - over a thousand genes - were ascribed to culture conditions and mainly to serum addition ( $n=1039 / 6746$, Heras et al. 2016). Despite the detrimental in vitro conditions, no developmental pause was observed in any of our in vitro-produced embryos. Indeed, in comparing the gene expression patterns from our embryos with those from a study of diapause in mice (Fu et al. 2014), the largest degree of overlap was not in genes associated with dormancy $(n=18)$, but those linked to reactivation at the end of dormancy $(n=72)$. We were thus surprised at the high number of DEGs ( $41 \%$ of genes overexpressed in IVP vs vivo) that were shared with mouse epiblast in diapause (as compared to WT epiblast and PrE at E4.5; Boroviak et al. 2015). The simplest explanation of this is that most of these genes are linked to the cellular machinery (cellular junctions, cell signalling, translation regulators, transporters), perhaps IVP embryos (as compared to vivo) engage pathways similar to those involved in ongoing diapause or a reactivation process at the end of dormancy (as compared to WTs). Whether embryonic adaptabilities could depend on such genes is an open question.

In conclusion, the current work found evidence for three main phenotypes. The patterns of gene enrichment we initially found seemed to confirm a phenotype for 'fully formed' blastocysts, but further investigation revealed that early- and late-forming blastocysts in fact appear to be quite different: they share a limited set of enriched genes and yield dramatically different survival rates when immediately transferred (58 vs $25 \%$ in D6-T6 vs D8-T8). Instead the ' +1 phenotype' was characterised by a shared gene enrichment set that was larger than that of the newly formed blastocysts, which argued for similar mechanisms of adaptation in both the D6 and D7 embryos to the in vitro environment. However, these adaptations did not 
appear to benefit the D7+1 embryos, as their survival rate at D18 was as low as that of the D8-T8 group: $25 \%$. The ' +2 phenotype' was defined by the highest number of differences with the D6 embryos, both in vitro (differential gene expression) and in vivo (increased IFN-tau production). Despite these differences, D6+2 embryos survived slightly better than the D8 or D7+1 embryos, even though all three groups were transferred at D8. Finally, it was clear that the D6 embryos were the most successful once transferred (recovery rate and IFNtau production equal to those of the in vivo control).

Regardless of the differences among the groups, the fact remains that no IVP group closely resembled D7 in vivo-developed blastocysts. One potential explanation could be that the IVP embryos engaged pathways partly similar to those of an ongoing diapause or a reactivation process at the end of dormancy. Much work remains to be done to decipher the abilities of in vitro-produced zygotes to adapt to culture conditions (del Collado et al. 2016, Desmet et al. 2016, Sutton-McDowall et al. 2016), the impact of such conditions upon developmental competence (Rizos et al. 2002) and their adaptive abilities in vivo. Although the intrinsic embryo viability was partly mirrored by the post-transfer phenotypes in this study, there is growing appreciation of the role that the uterine fluids play as in vivo modulators of embryonic viability (sensing/driving properties). Indeed, as a result of these sensor/driver properties (Bauersachs et al. 2009, Mansouri-Attia et al. 2009), the uterine milieu may alternatively (i) 'rescue' embryos by advancing development or minimising transcriptional differences (Clemente et al. 2009, Machado et al. 2013), (ii) induce novel transcriptional differences in embryos (Forde et al. 2017) or (iii) filter out suboptimal embryos to prevent unsuccessful implantation and later miscarriages (Macklon \& Brosens 2014). The next major goal for this field of research might therefore be a pairwise analysis of the intrinsic viability of embryos in the context of the uterine milieu in which they are transferred.

\section{Supplementary data}

This is linked to the online version of the paper at https://doi.org/10.1530/REP-18-0439.

\section{Declaration of interest}

Hue $\mathrm{I}$ is a member of the Editorial Board of Reproduction. The other authors declare that there is no conflict of interest that could be perceived as prejudicing the impartiality of the research reported.

\section{Funding}

This research did not receive any specific grant from any funding agency in the public, commercial or not-for-profit sector.

\section{Acknowledgements}

The authors thank $Y$ Heyman and $Y$ Lavergne (INRA, UMR BDR, France) for early discussions on and initiation of the IVP and ET work, J Marchal and C Richard for their contributions on the experimental farm (INRA, UE331, France), S Molly and $\mathrm{H}$ Langman (University of Bonn, Institute of Anatomy, Germany) for invaluable assistance and advice on WISH protocols, A Gad for his published dataset including the D7 in vivo embryos that we used as controls in our analyses, $V$ Duranthon (INRA, UMR BDR, France) for helpful discussions on array and qPCR data, S Calderari, G Charpigny, M Raliou (INRA, UMR BDR, France) for advice on GSEA, JF Oudin (INRA, UMR BDR, France) for in silico analyses inserted into rebuttal letter and L Higgins (English Services for Scientists) for English editing. They also acknowledge financial support from EU FP7 KBBE FECUND for A Vitorino Carvalho's research contribution and fellowship.

\section{References}

Alexopoulos NI, Maddox-Hyttel P, Tveden-Nyborg P, D'Cruz NT, Tecirlioglu TR, Cooney MA, Schauser K, Holland MK \& French AJ 2008 Developmental disparity between in vitro-produced and somatic cell nuclear transfer bovine days 14 and 21 embryos: implications for embryonic loss. Reproduction 136 433-445. (https://doi.org/10.1530/ REP-07-0392)

Barrera AD, García EV, Hamdi M, Sánchez-Calabuig MJ, LópezCardona ÁP, Balvís NF, Rizos D \& Gutiérrez-Adán A 2017 Embryo culture in presence of oviductal fluid induces DNA methylation changes in bovine blastocysts. Reproduction 154 1-12. (https://doi.org/10.1530/ REP-16-0651)

Bauersachs S, Ulbrich SE, Zakhartchenko V, Minten M, Reichenbach M, Reichenbach HD, Blum H, Spencer TE \& Wolf E 2009 The endometrium responds differently to cloned versus fertilized embryos. PNAS 106 5681-5686. (https://doi.org/10.1073/pnas.0811841106)

Bazer FW, Burghardt RC, Johnson GA, Spencer TE \& Wu G 2018 Mechanisms for the establishment and maintenance of pregnancy: synergies from scientific collaborations. Biology of Reproduction 99 225-241. (https://doi.org/10.1093/biolre/ioy047)

Benjamini Y 1995 Controlling the false discovery rate: a practical and powerful approach to multiple testing. Journal of the Royal Statistical Society: Series B (Methodological) 57 289-300.

Berg DK, van Leeuwen J, Beaumont S, Berg M \& Pfeffer PL 2010 Embryo loss in cattle between days 7 and 16 of pregnancy. Theriogenology 73 250-260. (https://doi.org/10.1016/j.theriogenology.2009.09.005)

Bertoldo MJ, Locatelli Y, O'Neill C \& Mermillod P 2015 Impacts of and interactions between environmental stress and epigenetic programming during early embryo development. Reproduction, Fertility, and Development 27 1125-1136. (https://doi.org/10.1071/RD14049)

Bertolini M, Beam SW, Shim H, Bertolini LR, Moyer AL, Famula TR \& Anderson GB 2002 Growth, development, and gene expression by in vivo- and in vitro-produced day 7 and 16 bovine embryos. Molecular Reproduction and Development 63 318-328. (https://doi.org/10.1002/ mrd.90015)

Boroviak T, Loos R, Lombard P, Okahara J, Behr R, Sasaki E, Nichols J, Smith A \& Bertone P 2015 Lineage-specific profiling delineates the emergence and progression of naive pluripotency in mammalian embryogenesis. Developmental Cell 35 366-382. (https://doi. org/10.1016/j.devcel.2015.10.011)

Cagnone G \& Sirard MA 2016 The embryonic stress response to in vitro culture: insight from genomic analysis. Reproduction 152 R247-R261. (https://doi.org/10.1530/REP-16-0391)

Catt JW 1994 Bovine embryo co-culture. Cell Biology International 18 1155-1162. (https://doi.org/10.1006/cbir.1994.1042)

Clemente $M$, de La Fuente J, Fair T, Al Naib A, Gutierrez-Adan A, Roche JF, Rizos D \& Lonergan P 2009 Progesterone and conceptus elongation in cattle: a direct effect on the embryo or an indirect effect via 
the endometrium? Reproduction 138 507-517. (https://doi.org/10.1530/ REP-09-0152)

Cordova A, Perreau C, Uzbekova S, Ponsart C, Locatelli Y \& Mermillod P 2014 Development rate and gene expression of IVP bovine embryos cocultured with bovine oviduct epithelial cells at early or late stage of preimplantation development. Theriogenology 81 1163-1173. (https:// doi.org/10.1016/j.theriogenology.2014.01.012)

Degrelle SA, Jaffrezic F, Campion E, Le Cao KA, Le Bourhis D, Richard C, Rodde N, Fleurot R, Everts RE, Lecardonnel J et al. 2012 Uncoupled embryonic and extra-embryonic tissues compromise blastocyst development after somatic cell nuclear transfer. PLOS ONE 7 e38309. (https://doi.org/10.1371/journal.pone.0038309)

del Collado M, Saraiva NZ, Lopes FL, Gaspar RC, Padilha LC, Costa RR, Rossi GF, Vantini R \& Garcia JM 2016 Influence of bovine serum albumin and fetal bovine serum supplementation during in vitro maturation on lipid and mitochondrial behaviour in oocytes and lipid accumulation in bovine embryos. Reproduction, Fertility and Development 281721. (https://doi.org/10.1071/RD15067)

Desai N \& Goldfarb J 1998 Co-cultured human embryos may be subjected to widely different microenvironments: pattern of growth factor/cytokine release by Vero cells during the co-culture interval. Human Reproduction 13 1600-1605. (https://doi.org/10.1093/humrep/13.6.1600)

Desmet KLJ, Van Hoeck V, Gagné D, Fournier E, Thakur A, O'Doherty AM, Walsh CP, Sirard MA, Bols PEJ \& Leroy JLMR 2016 Exposure of bovine oocytes and embryos to elevated non-esterified fatty acid concentrations: integration of epigenetic and transcriptomic signatures in resultant blastocysts. BMC Genomics 17 1004. (https://doi.org/10.1186/s12864016-3366-y)

Dray S \& Dufour AB 2007 The ade4 package: implementing the duality diagram for ecologists. Journal of Statistical Software 22 1-20. (https:// doi.org/10.18637/jss.v022.i04)

Duranthon V \& Chavatte-Palmer P 2018 Long term effects of ART: what do animals tell us? Molecular Reproduction and Development 85 348-368. (https://doi.org/10.1002/mrd.22970)

Ealy AD \& Yang QE 2009 Control of interferon-tau expression during early pregnancy in ruminants. American Journal of Reproductive Immunology 61 95-106. (https://doi.org/10.1111/j.1600-0897.2008.00673.x)

El-Sayed A, Hoelker M, Rings F, Salilew D, Jennen D, Tholen E, Sirard MA, Schellander K \& Tesfaye D 2006 Large-scale transcriptional analysis of bovine embryo biopsies in relation to pregnancy success after transfer to recipients. Physiological Genomics 28 84-96. (https://doi.org/10.1152/ physiolgenomics.00111.2006)

Farin CE, Hasler JF, Martus NS \& Stokes JE 1997 A comparison of Menezo's B2 and tissue culture Medium-199 for in vitro production of bovine blastocysts. Theriogenology $\mathbf{4 8}$ 699-709. (https://doi.org/10.1016/ S0093-691X(97)00294-X)

Farin PW, Crosier AE \& Farin CE 2001 Influence of in vitro systems on embryo survival and fetal development in cattle. Theriogenology $\mathbf{5 5}$ 151-170. (https://doi.org/10.1016/S0093-691X(00)00452-0)

Fenelon JC, Banerjee A \& Murphy BD 2014 Embryonic diapause: development on hold. International Journal of Developmental Biology 58 163-174. (https://doi.org/10.1387/ijdb.140074bm)

Feuer SK, Liu X, Donjacour A, Simbulan R, Maltepe E \& Rinaudo P 2017 Transcriptional signatures throughout development: the effects of mouse embryo manipulationin vitro. Reproduction 153 107-122. (https://doi. org/10.1530/REP-16-0473)

Fischer-Brown AE, Lindsey BR, Ireland FA, Northey DL, Monson RL, Clark SG, Wheeler MB, Kesler DJ, Lane SJ, Weigel KA et al. 2004 Embryonic disc development and subsequent viability of cattle embryos following culture in two media under two oxygen concentrations. Reproduction, Fertility, and Development 16 787-793. (https://doi. org/10.1071/RD04026)

Forde N, Simintiras CA, Sturmey RG, Graf A, Wolf E, Blum H \& Lonergan P 2017 Effect of lactation on conceptus-maternal interactions at the initiation of implantation in cattle: I. Effects on the conceptus transcriptome and amino acid composition of the uterine luminal fluid. Biology of Reproduction 97 798-809. (https://doi.org/10.1093/biolre/ iox135)

Fu Z, Wang B, Wang S, Wu W, Wang Q, Chen Y, Kong S, Lu J, Tang Z, Ran H et al. 2014 Integral proteomic analysis of blastocysts reveals key molecular machinery governing embryonic diapause and reactivation for implantation in mice. Biology of Reproduction 90 52. (https://doi. org/10.1095/biolreprod.113.115337)

Gad A, Hoelker M, Besenfelder U, Havlicek V, Cinar U, Rings F, Held E, Dufort I, Sirard M-A, Schellander K et al. 2012a Molecular mechanisms and pathways involved in bovine embryonic genome activation and their regulation by alternative in vivo and in vitro culture conditions. Biology of Reproduction 87 100. (https://doi.org/10.1095/biolreprod.112.099697)

Gad A, Schellander K, Hoelker M \& Tesfaye D 2012b Transcriptome profile of early mammalian embryos in response to culture environment. Animal Reproduction Science 134 76-83. (https://doi.org/10.1016/j. anireprosci.2012.08.014)

Gentleman RC, Carey VJ, Bates DM, Bolstad B, Dettling M, Dudoit S, Ellis B, Gautier L, Ge Y, Gentry J et al. 2004 Bioconductor: open software development for computational biology and bioinformatics. Genome Biology 5 R80. (https://doi.org/10.1186/gb-2004-5-10-r80)

Ghanem N, Salilew-Wondim D, Gad A, Tesfaye D, Phatsara C, Tholen E, Looft C, Schellander K \& Hoelker M 2011 Bovine blastocysts with developmental competence to term share similar expression of developmentally important genes although derived from different culture environments. Reproduction 142 551-564. (https://doi.org/10.1530/ REP-10-0476)

Gutierrez-Adan A, White CR, Van Soom A \& Mann MRW 2015 Why we should not select the faster embryo: lessons from mice and cattle. Reproduction, Fertility and Development 27 765. (https://doi. org/10.1071/RD14216)

Hamdi M, Lopera-Vasquez R, Maillo V, Sanchez-Calabuig MJ, Núnez C, Gutierrez-Adan A \& Rizos D 2018 Bovine oviductal and uterine fluid support in vitro embryo development. Reproduction, Fertility and Development 30 935. (https://doi.org/10.1071/RD17286)

Hasler JF 2000 In vitro culture of bovine embryos in Menezo's B2 medium with or without coculture and serum: the normalcy of pregnancies and calves resulting from transferred embryos. Animal Reproduction Science 60-61 81-91. (https://doi.org/10.1016/S0378-4320(00)00086-5)

Hasler JF 2014 Forty years of embryo transfer in cattle: a review focusing on the journal theriogenology, the growth of the industry in North America, and personal reminisces. Theriogenology 81 152-169. (https:// doi.org/10.1016/j.theriogenology.2013.09.010)

Heras S, De Coninck DIM, Van Poucke M, Goossens K, Bogado Pascottini O, Van Nieuwerburgh F, Deforce D, De Sutter P, Leroy JLMR, Gutierrez-Adan A et al. 2016 Suboptimal culture conditions induce more deviations in gene expression in male than female bovine blastocysts. BMC Genomics 17 72. (https://doi.org/10.1186/s12864016-2393-z)

Hoelker M, Schmoll F, Schneider H, Rings F, Gilles M, Tesfaye D, Jennen D, Tholen E, Griese J \& Schellander K 2006 Bovine blastocyst diameter as a morphological tool to predict embryo cell counts, embryo sex, hatching ability and developmental characteristics after transfer to recipients. Reproduction, Fertility, and Development 18 551-557. (https://doi. org/10.1071/RD05149)

Hosseini SM, Dufort I, Caballero J, Moulavi F, Ghanaei HR \& Sirard MA 2015 Transcriptome profiling of bovine inner cell mass and trophectoderm derived from in vivo generated blastocysts. BMC Developmental Biology 15 (https://doi.org/10.1186/s12861-015-0096-3)

Hue I 2016 Determinant molecular markers for peri-gastrulating bovine embryo development. Reproduction, Fertility, and Development 28 51-65. (https://doi.org/10.1071/RD15355)

Hue I, Renard JP \& Viebahn C 2001 Brachyury is expressed in gastrulating bovine embryos well ahead of implantation. Development Genes and Evolution 211 157-159. (https://doi.org/10.1007/s004270100138)

Hue I, Degrelle SA \& Viebahn C 2013 Analysis of molecular markers for staging peri-gastrulating bovine embryos. Methods in Molecular Biology 1074 125-135. (https://doi.org/10.1007/978-1-62703-628-3_10)

Hue I, Evain-Brion D, Fournier T \& Degrelle SA 2015 Primary bovine extra-embryonic cultured cells: a new resource for the study of in vivo peri-implanting phenotypes and mesoderm formation. PLOS ONE 10 e0127330. (https://doi.org/10.1371/journal.pone.0127330)

Jones AL \& Lamb GC 2008 Nutrition, synchronization, and management of beef embryo transfer recipients. Theriogenology 69 107-115. (https:// doi.org/10.1016/j.theriogenology.2007.09.004)

Khan DR, Fournier É, Dufort I, Richard FJ, Singh J \& Sirard M-A 2016 Meta-analysis of gene expression profiles in granulosa cells 
during folliculogenesis. Reproduction 151 R103-R110. (https://doi. org/10.1530/REP-15-0594)

Lonergan P, Fair T, Forde N \& Rizos D 2016 Embryo development in dairy cattle. Theriogenology 86 270-277. (https://doi.org/10.1016/j. theriogenology.2016.04.040)

Machado GM, Ferreira AR, Pivato I, Fidelis A, Spricigo JF, Paulini F, Lucci CM, Franco MM \& Dode MA 2013 Post-hatching development of in vitro bovine embryos from day 7 to 14 in vivo versus in vitro. Molecular Reproduction and Development 80 936-947. (https://doi. org/10.1002/mrd.22230)

Macklon NS \& Brosens JJ 2014 The human endometrium as a sensor of embryo quality. Biology of Reproduction 91 98. (https://doi.org/10.1095/ biolreprod.114.122846)

Maddox-Hyttel P, Alexopoulos NI, Vajta G, Lewis I, Rogers P, Cann L, Callesen H, Tveden-Nyborg P \& Trounson A 2003 Immunohistochemical and ultrastructural characterization of the initial post-hatching development of bovine embryos. Reproduction 125 607-623. (https:// doi.org/10.1530/rep.0.1250607)

Mamo S, Mehta JP, McGettigan P, Fair T, Spencer TE, Bazer FW \& Lonergan P 2011 RNA sequencing reveals novel gene clusters in bovine conceptuses associated with maternal recognition of pregnancy and implantation. Biology of Reproduction 85 1143-1151. (https://doi. org/10.1095/biolreprod.111.092643)

Mansouri-Attia N, Sandra O, Aubert J, Degrelle S, Everts RE, GiraudDelville C, Heyman Y, Galio L, Hue I, Yang X et al. 2009 Endometrium as an early sensor of in vitro embryo manipulation technologies. PNAS 106 5687-5692. (https://doi.org/10.1073/pnas.0812722106)

Menck MC, Guyader-Joly C, Peynot N, Le Bourhis D, Lobo RB, Renard JP \& Heyman Y 1997 Beneficial effects of Vero cells for developing IVF bovine eggs in two different coculture systems. Reproduction Nutrition Development 37 141-150. (https://doi.org/10.1051/rnd:19970202)

Menezo YJ, Guerin JF \& Czyba JC 1990 Improvement of human early embryo development in vitro by coculture on monolayers of Vero cells. Biology of Reproduction 42 301-306. (https://doi.org/10.1095/ biolreprod42.2.301)

Mori M, Otoi T \& Suzuki T 2002 Correlation between the cell number and diameter in bovine embryos produced in vitro. Reproduction in Domestic Animals 37 181-184. (https://doi.org/10.1046/j.14390531.2002.00354.x)

Murillo A, Muñoz M, Martín-González D, Carrocera S, Martínez-Nistal A \& Gómez E 2017 Low serum concentration in bovine embryo culture enhances early blastocyst rates on day- 6 with quality traits in the expanded blastocyst stage similar to BSA-cultured embryos. Reproductive Biology 17 162-171. (https://doi.org/10.1016/j.repbio.2017.04.002)

Murillo-Rios A, Maillo V, Muñoz M, Gutiérrez-Adán A, Carrocera S, Martín-González D, Fernandez-Buznego A \& Gómez E 2017 Short- and long-term outcomes of the absence of protein during bovine blastocyst formation in vitro. Reproduction, Fertility and Development 291064. (https://doi.org/10.1071/RD15485)

Nagatomo H, Kagawa S, Kishi Y, Takuma T, Sada A, Yamanaka Ki, Abe Y, Wada Y, Takahashi M, Kono T et al. 2013 Transcriptional wiring for establishing cell lineage specification at the blastocyst stage in cattle. Biology of Reproduction 88 158. (https://doi.org/10.1095/ biolreprod.113.108993)

Negrón-Pérez VM, Zhang Y \& Hansen PJ 2017 Single-cell gene expression of the bovine blastocyst. Reproduction 154 627-644. (https://doi. org/10.1530/rep-17-0345)

Ozawa M, Sakatani M, Yao J, Shanker S, Yu F, Yamashita R, Wakabayashi S, Nakai K, Dobbs KB, Sudano M et al. 2012 Global gene expression of the inner cell mass and trophectoderm of the bovine blastocyst. BMC Developmental Biology 12 33. (https://doi.org/10.1186/1471213X-12-33)

Peynot N, Duranthon V \& Khan DR 2015 Gene expression analysis in early embryos through reverse transcription quantitative PCR (RTqPCR). Methods in Molecular Biology 1222 181-196. (https://doi. org/10.1007/978-1-4939-1594-1_14)

Plourde D, Vigneault C, Laflamme I, Blondin P \& Robert C 2012a Cellular and molecular characterization of the impact of laboratory setup on bovine in vitro embryo production. Theriogenology 77 1767.e1-1778. e1. (https://doi.org/10.1016/j.theriogenology.2011.12.021)

Plourde D, Vigneault C, Lemay A, Breton L, Gagne D, Laflamme I, Blondin P \& Robert C 2012b Contribution of oocyte source and culture conditions to phenotypic and transcriptomic variation in commercially produced bovine blastocysts. Theriogenology 78 116.e1-131.e3. (https://doi.org/10.1016/j.theriogenology.2012.01.027)

Randi F, Fernandez-Fuertes B, McDonald M, Forde N, Kelly AK, Bastos Amorin H, Muniz de Lima E, Morotti F, Marcondes Seneda M \& Lonergan P 2016 Asynchronous embryo transfer as a tool to understand embryo-uterine interaction in cattle: is a large conceptus a good thing? Reproduction, Fertility and Development 28 1999. (https://doi. org/10.1071/RD15195)

Richard C, Hue I, Gelin V, Neveux A, Campion E, Degrelle SA, Heyman Y \& Chavatte-Palmer P 2015 Transcervical collection of bovine embryos up to day 21: an 8-year overview. Theriogenology 83 1101-1109. (https://doi.org/10.1016/j.theriogenology.2014.12.005)

Rief S, Sinowatz F, Stojkovic M, Einspanier R, Wolf E \& Prelle K 2002 Effects of a novel co-culture system on development, metabolism and gene expression of bovine embryos produced in vitro. Reproduction 124 543-556. (https://doi.org/10.1530/rep.0.1240543)

Rizos D, Ward F, Duffy P, Boland MP \& Lonergan P 2002 Consequences of bovine oocyte maturation, fertilization or early embryo development in vitro versus in vivo: implications for blastocyst yield and blastocyst quality. Molecular Reproduction and Development 61 234-248. (https:// doi.org/10.1002/mrd.1153)

Robert C, Nieminen J, Dufort I, Gagne D, Grant JR, Cagnone G, Plourde D, Nivet AL, Fournier E, Paquet E et al. 2011 Combining resources to obtain a comprehensive survey of the bovine embryo transcriptome through deep sequencing and microarrays. Molecular Reproduction and Development 78 651-664. (https://doi.org/10.1002/mrd.21364)

Sakurai T, Sakamoto A, Muroi Y, Bai H, Nagaoka K, Tamura K, Takahashi T, Hashizume K, Sakatani M, Takahashi M et al. 2009 Induction of endogenous interferon tau gene transcription by CDX2 and high acetylation in bovine nontrophoblast cells. Biology of Reproduction $\mathbf{8 0}$ 1223-1231. (https://doi.org/10.1095/biolreprod.108.073916)

Sakurai T, Bai H, Bai R, Sato D, Arai M, Okuda K, Ideta A, Aoyagi Y, Godkin JD \& Imakawa K 2013 Down-regulation of interferon tau gene transcription with a transcription factor, EOMES. Molecular Reproduction and Development 80 371-383. (https://doi.org/10.1002/ mrd.22171)

Salilew-Wondim D, Fournier E, Hoelker M, Saeed-Zidane M, Tholen E, Looft C, Neuhoff C, Besenfelder U, Havlicek V, Rings F et al. 2015 Genome-wide DNA methylation patterns of bovine blastocysts developed in vivo from embryos completed different stages of development in vitro. PLOS ONE 10 e0140467. (https://doi.org/10.1371/ journal.pone.0140467)

Salvaing J, Peynot N, Bedhane MN, Veniel S, Pellier E, Boulesteix C, Beaujean N, Daniel N \& Duranthon V 2016 Assessment of 'one-step' versus 'sequential' embryo culture conditions through embryonic genome methylation and hydroxymethylation changes. Human Reproduction 31 2471-2483. (https://doi.org/10.1093/humrep/dew214)

Schmaltz-Panneau B, Locatelli Y, Uzbekova S, Perreau C \& Mermillod P 2015 Bovine oviduct epithelial cells dedifferentiate partly in culture, while maintaining their ability to improve early embryo development rate and quality. Reproduction in Domestic Animals 50 719-729. (https://doi.org/10.1111/rda.12556)

Sinclair KD, McEvoy TG, Maxfield EK, Maltin CA, Young LE, Wilmut I, Broadbent PJ \& Robinson JJ 1999 Aberrant fetal growth and development after in vitro culture of sheep zygotes. Journal of Reproduction and Fertility 116 177-186. (https://doi.org/10.1530/jrf.0.1160177)

Smyth GK 2005 Limma: linear models for microarray data. In Bioinformatics and Computational Biology Solutions Using $R$ and Bioconductor, pp 397-420.

Stroebech L, Mazzoni G, Pedersen HS, Freude KK, Kadarmideen H, Callesen H \& Hyttel P 2015 In vitro production of bovine embryos: revisiting oocyte development and application of systems biology. Animal Reproduction 12 465-472.

Subramanian A, Tamayo P, Mootha VK, Mukherjee S, Ebert BL, Gillette MA, Paulovich A, Pomeroy SL, Golub TR, Lander ES et al. 2005 Gene set enrichment analysis: a knowledge-based approach for interpreting genome-wide expression profiles. PNAS 102 15545-15550. (https://doi. org/10.1073/pnas.0506580102)

Sutton-McDowall ML, Wu LLY, Purdey M, Abell AD, Goldys EM, MacMillan KL, Thompson JG \& Robker RL 2016 Nonesterified fatty acidinduced endoplasmic reticulum stress in cattle cumulus oocyte complexes 
alters cell metabolism and developmental competence. Biology of Reproduction 94 23. (https://doi.org/10.1095/biolreprod.115.131862)

Thompson JG, Mitchell M \& Kind KL 2007 Embryo culture and long-term consequences. Reproduction, Fertility, and Development 19 43-52. (https://doi.org/10.1071/RD06129)

Thompson JG, Brown HM \& Sutton-McDowall ML 2016 Measuring embryo metabolism to predict embryo quality. Reproduction, Fertility and Development 28 41. (https://doi.org/10.1071/RD15340)

van Leeuwen J, Berg DK \& Pfeffer PL 2015 Morphological and gene expression changes in cattle embryos from hatched blastocyst to early gastrulation stages after transfer of in vitro produced embryos. PLoS ONE 10 e0129787. (https://doi.org/10.1371/journal.pone.0129787)

Vitorino Carvalho A, Canon E, Jouneau L, Archilla C, Laffont L, Moroldo M, Ruffini S, Corbin E, Mermillod P \& Duranthon V 2017 Different co-culture systems have the same impact on bovine embryo transcriptome. Reproduction 154 695-710. (https://doi.org/10.1530/ REP-17-0449)

Webb AE, Kundaje A \& Brunet A 2016 Characterization of the direct targets of FOXO transcription factors throughout evolution. Aging Cell 15 673-685. (https://doi.org/10.1111/acel.12479)

Wei Q, Zhong L, Zhang S, Mu H, Xiang J, Yue L, Dai Y \& Han J 2017 Bovine lineage specification revealed by single-cell gene expression analysis from zygote to blastocyst. Biology of Reproduction 97 5-17. (https://doi.org/10.1093/biolre/iox071)
Wrenzycki C, Herrmann D, Keskintepe L, Martins A Jr, Sirisathien S, Brackett B \& Niemann H 2001 Effects of culture system and protein supplementation on mRNA expression in pre-implantation bovine embryos. Human Reproduction 16 893-901. (https://doi.org/10.1093/ humrep/16.5.893)

Xavier F, Lagarrigue S, Guillomot M \& Gaillard-Sanchez I 1997 Expression of $\mathrm{c}-\mathrm{fos}$ and jun protooncogenes in ovine trophoblasts in relation to interferon-tau expression and early implantation process. Molecular Reproduction and Development 46 127-137. (https://doi.org/10.1002/ (SICI)1098-2795(199702)46:2<127::AID-MRD3>3.0.CO;2-S)

Zhao XM, Cui LS, Hao HS, Wang HY, Zhao SJ, Du WH, Wang D, Liu Y \& Zhu HB 2016 Transcriptome analyses of inner cell mass and trophectoderm cells isolated by magnetic-activated cell sorting from bovine blastocysts using single cell RNA-seq. Reproduction in Domestic Animals 51 726-735. (https://doi.org/10.1111/rda.12737)

Received 20 August 2018

First decision 28 September 2018

Revised manuscript received 31 October 2018

Accepted 13 November 2018 